HAMILTON JOSÉ SALES FONTE ॥

\title{
DIZANG: UMA SOLUÇÃO PARA COLETA DE EVIDÊNCIAS FORENSES PARA ATAQUES DE INJEÇÃO NA NUVEM
}

\author{
Versão Corrigida \\ (Versão original encontra-se na unidade que aloja o Programa de \\ Pós-graduação) \\ Dissertação apresentada à Escola \\ Politécnica da Universidade de São \\ Paulo para a obtenção do Título de \\ Mestre em Ciência.
}

São Paulo

2020 
HAMILTON JOSÉ SALES FONTE ॥

\title{
DIZANG: UMA SOLUÇÃO PARA COLETA DE EVIDÊNCIAS FORENSES PARA ATAQUES DE INJEÇÃO NA NUVEM
}

\author{
Versão Corrigida \\ (Versão original encontra-se na unidade que aloja o Programa de \\ Pós-graduação)
}

Dissertação apresentada à Escola Politécnica da Universidade de São Paulo para a obtenção do Título de Mestre em Ciência.

Área de concentração:

Engenharia da Computação

Orientador:

Marcos Antonio Simplício Junior

São Paulo

2020 
Autorizo a reprodução e divulgação total ou parcial deste trabalho, por qualquer meio convencional ou eletrônico, para fins de estudo e pesquisa, desde que citada a fonte.

Este exemplar foi revisado e corrigido em relação à versão original, sob responsabilidade única do autor e com a anuência de seu orientador.

São Paulo, de de

Assinatura do autor:

Assinatura do orientador:

Fonte II, Hamilton

DIZANG: UMA SOLUÇÃO PARA COLETA DE EVIDÊNCIAS FORENSES

PARA ATAQUES DE INJEÇÃO NA NUVEM / H. Fonte II, M. Simplício Jr -versão corr. -- São Paulo, 2020.

$65 \mathrm{p}$.

Dissertação (Mestrado) - Escola Politécnica da Universidade de São Paulo. Departamento de Engenharia de Computação e Sistemas Digitais.

1.COMPUTAÇÃO EM NUVEM 2.ANÁLISE FORENSE 3.CONTÊINER 4.COLETA DE EVIDÊNCIAS I.Universidade de São Paulo. Escola Politécnica. Departamento de Engenharia de Computação e Sistemas Digitais II.t. III.Simplício Jr, Marcos 
A minha esposa e filha, pelas noites e finais de semana que não estive com vocês durante a elaboração deste trabalho. 


\section{AGRADECIMENTOS}

As Deus por ter dado sua benção durante todo momento para que eu pudesse continuar meus estudos.

A minha família pelo apoio incondicional.

Ao meu orientador o Prof. Dr. Marcos Simplício, que me amparou e conduziu nesta jornada.

A Universidade de São Paulo, a Escola Politécnica e o Programa de Pós Graduação, por ter me acolhido como aluno de mestrado. 


\section{RESUMO}

A adoção de arquiteturas em nuvem aumenta a cada dia, e proporcionalmente aumenta também o número de casos em que esse tipo de tecnologia é usada para fins ilícitos. Infelizmente, devido à natureza volátil da nuvem, a tarefa de coletar evidências para análise forense nesse ambiente tem esbarrado em desafios práticos e legais. Mais precisamente, a prática herdada da forense tradicional para coleta de evidências, por meio da qual se isola a cena do crime e coletam-se todas as evidências, foi traduzida para a forense digital como a cópia bit a bit da mídia que se deseja investigar. Tal prática leva à coleta de grandes volumes de informação para análise, impactando negativamente o tempo de investigação. Além disso, duas características das soluções em nuvem dificultam a obtenção de evidências forensicamente confiáveis, além de atrapalhar o processo de análise de incidentes de modo geral. A primeira é que o compartilhamento de recursos físicos entre vários usuários impede a sua remoção para análise, uma vez que isso violaria a privacidade de indivíduos não envolvidos na investigação. A segunda é que a localização do recurso físico em uma região geográfica diferente daquela onde o crime foi cometido pode impedir a coleta de evidências caso não haja acordos de cooperação estabelecidos. Estes aspectos, se não forem levados em consideração, podem colocar em dúvida a credibilidade das evidências e diminuir a chance de serem aceitas em um processo legal. Este trabalho analisa propostas na literatura voltadas a resolver tais desafios na coleta evidências na nuvem, discutindo suas limitações. Propõe-se, então, uma solução que cobre coleta, transporte e armazenamento da evidência, visando suplantar as limitações existentes no estado da arte. A solução proposta, denominada Dizang, provê uma forma de correlacionar evidências e sua origem virtual, permitindo transportar e armazenar tais dados sem afetar sua credibilidade. Para tal, é proposto um mecanismo de identificação única do gerador da evidência, permitindo então preservar a relação evidência-origem mesmo que esta última não exista mais no ambiente sob investigação. Em resumo, Dizang tem como focos (1) a reprodutibilidade do processo de coleta, (2) o estabelecimento de um vínculo entre a evidência coletada e sua origem, (3) a preservação da jurisdição e da privacidade de usuários não envolvidos na investigação e (4) a garantia de custódia da evidência. 


\begin{abstract}
The adoption of cloud architectures is increasing day by day, and proportionally increases the number of cases in which this technology is used for illicit purposes. Unfortunately, due to the volatile nature of the cloud, the task of collecting evidences for forensic analysis in this environment has run into practical and legal challenges. The practice inherited from the traditional forensics, through which the crime scene is isolated and all the evidence is collected, was carried to digital forensics as the bitwise copy of the media to be investigated. Such practice leads to the collection of large volumes of information for analysis, negatively impacting the investigation time. In addition, two characteristics of cloud solutions make it difficult to obtain forensically reliable evidence and disrupt the overall incident analysis process. The first is that the sharing of physical resources among multiple users prevents their removal for analysis as this would violate the privacy of individuals not involved in the investigation. The second is that the location of the physical resource in a different geographic region from where the crime was committed may prevent the collection of evidence if no cooperation agreements are in place. These aspects, if not taken into consideration, may undermine the credibility of the evidence and decrease the likelihood of their acceptance in a legal process. This work, analyzes proposals found in the literature aimed at solving such challenges, discussing its limitations. It proposes a solution that covers collection-gathering, transportation and storage of evidence, aiming at overcoming existing limitations in the state of art. The proposed solution, called Dizang, provides a way of correlating evidence and its virtual origin, allowing the transport and storage of such data without affecting its credibility. For this, it proposes a mechanism to identify uniquely the source of the evidence, in order to preserve the relationship evidence-source even though the latter does not exist in the system under investigation. In summary, Dizang focuses on (1) the reproducibility of the collection process, (2)the establishment of a link between the evidence collected and its origin, (3) the preservation of jurisdiction and privacy of users not involved in the investigation and (4)the evidence's chain of custody.
\end{abstract}




\section{LISTA DE ILUSTRAÇÕES}

1 Modelo Automático de Aquisição de Dados Forenses . . . . . . . . . 29

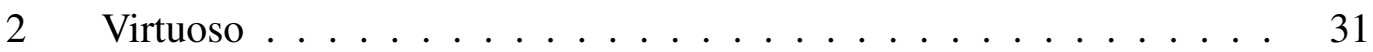

3 A Log Based Approach Model . . . . . . . . . . . . . . . . . . . 32

$4 \quad$ Backup Approach Model . . . . . . . . . . . . . . . . 33

5 FoRensic OpenStack Tools .................. . . 35

6 Digital Forensic Framework for Cloud Environment . . . . . . . . . . 37

$7 \quad$ Digital Forensic as a Service - Indexed Data . . . . . . . . . . . . 38

8 Janela deslizante de coleta de evidência . . . . . . . . . . . 45

9 Arquitetura geral da solução Dizang . . . . . . . . . . . . . . 47

10 Fluxo de execução de Dizang para 1 hospedeiro de contêiner . . . . . 49

11 Evolução do uso do espaço em armazenamento com o Dizang . . . . 51

12 Tempo de cópia da memória de um contêiner . . . . . . . . . . . 52

13 Tempo de transporte da evidência $\ldots \ldots \ldots 53$

14 Comando para cópia crua da memória do processo do contêiner . . . 54

15 Parte do arquivo /proc/pid/numa_maps ANTES da injeção . . . . . 54

16 Parte do arquivo /proc/pid/numa_maps APÓS a injeção . . . . . . . 55

17 Conteúdo da memória de libexample.so no formato [endereço]: [conteúdo $\ldots \ldots \ldots \ldots \ldots \ldots \ldots \ldots$ 


\section{LISTA DE TABELAS}

1 Comparativo de soluções de coleta de informações de memória de máquinas em nuvem para análise forense . . . . . . . . . . . . 42 


\section{LISTA DE ABREVIATURAS E SIGLAS}

\begin{tabular}{|c|c|}
\hline API & Aplication Programing Interface \\
\hline CSP & Cloud Service Provider \\
\hline EDIPM & Enhanced Digital Investigation Process Model \\
\hline ETL & Extract, Transform and Load \\
\hline FROST & FoRensic Open Stack Tools \\
\hline GDB & GNU Debugger \\
\hline GRR & Google Rapid Response \\
\hline IaaS & Infrastructure as a Service \\
\hline LXC & Linux Conteiners \\
\hline NAS & Network Accessed Storage \\
\hline $\mathrm{PaaS}$ & Platform as a Service \\
\hline SaaS & Software as a Service \\
\hline $\mathrm{SO}$ & Sistema Operacional \\
\hline SWGDE & Scientific Working Group on Digital Evidence \\
\hline $\mathrm{VM}$ & Virtual Machine \\
\hline VMI & Virtual Machine Introspection \\
\hline VMM & Virtual Machine Manager \\
\hline
\end{tabular}




\section{SUMÁRIO}

1 Introdução 11

1.1 Motivação . . . . . . . . . . . . . . . . . . . . . . 12

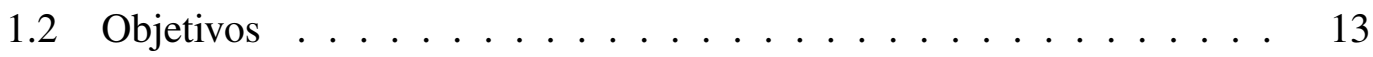

1.3 Justificativa . . . . . . . . . . . . . . . . . . 13

1.4 Método . . . . . . . . . . . . . . . . . . . . . . 14

1.5 Organização do documento . . . . . . . . . . . . . . . . . . 15

2 Fundamentação Teórica $\quad 16$

2.1 Nuvens computacionais e contêineres . . . . . . . . . . . 17

2.2 Forense digital e seus desafios $\ldots \ldots \ldots$

2.2.1 Admissibilidade da evidência em processo legal. . . . . . . . 20

2.2.2 Volume de dados para coleta . . . . . . . . . . . . 22

2.2 .3 Privacidade e jurisdição . . . . . . . . . . . . . 23

2.2.4 Coleta de evidências de memória volátil de máquinas em nuvem 23

2.3 Forense digital e gestão de incidentes . . . . . . . . . . . . . 25

3 Revisão da literatura $\quad 27$

3.1 Soluções para análise forense em nuvem . . . . . . . . . . . . . . . 27

3.1.1 Modelo automático de aquisição de dados para fins forenses . $\quad 27$

3.1 .2 Introspecção em máquina virtual . . . . . . . . . . . 28 
3.1 .3 Virtuoso .......................... 30

3.1.4 Abordagem baseada em logs . . . . . . . . . . . . 30

3.1.5 Abordagem baseada em backups . . . . . . . . . . 32

3.1.6 Arcabouço forense para OpenStack . . . . . . . . . 34

3.1 .7 Forense como serviço $\ldots \ldots \ldots \ldots$

3.1.8 Abordagem de indexação de dados coletados para fins forenses 36

3.2 Aspectos relacionados a coleta de evidência . . . . . . . . . . 38

3.2.1 Acessar e coletar as informações de memória das máquinas virtuais em nuvem . . . . . . . . . . . 38

3.2.2 Capacidade de reproduzir o processo e obter os mesmos resul$\operatorname{tad} 0 . \ldots \ldots \ldots \ldots \ldots \ldots$

3.2.3 Não violar privacidade ou jurisdição das partes não envolvidas na investigação . . . . . . . . . . . . . . 4 40

3.2.4 Garantir a cadeia de custódia da evidência . . . . . . . . . . 41

3.3 Resumo .......................... 41

4 Proposta de projeto: Dizang 43

4.1 Identificação da origem . . . . . . . . . . . . . . . . . 43

4.2 Descrever o sistema antes e depois do incidente . . . . . . . . . . 44

4.3 Garantindo integridade, confidencialidade e protegendo privacidade e jurisdição . . . . . . . . . . . . . . . . . . 46

4.4 Implementação . . . . . . . . . . . . . . . . . . 46

4.5 Resultados experimentais . . . . . . . . . . . . . . . . 48 
4.5.1 Análise do desempenho . . . . . . . . . . . . . . 48

4.5.2 Identificação de injeção de código malicioso . . . . . . . . . 53

4.6 Limitações . . . . . . . . . . . . . . . . . . . . . . . 56

5 Conclusões $\quad 58$

5.1 Trabalhos Futuros . . . . . . . . . . . . . . . . . . 59

$\begin{array}{ll}\text { Referências } & 61\end{array}$ 


\section{INTRODUÇÃO}

Técnicas de virtualização, replicação de serviços e compartilhamento de recursos entre múltiplos usuários (multi-inquilinato) proveem a nuvens computacionais uma elevada escalabilidade (MORSY; GRUNDY; MULLER, 2010). Ao mesmo tempo, tais mecanismos também tornam voláteis os recursos virtuais que executam aplicações em nuvem. Afinal, quando submetida a uma carga elevada, uma aplicação hospedada na nuvem pode criar instâncias das máquinas virtuais que a hospedam e balancear a carga entre elas. Isso permite ao sistema em nuvem ter elasticidade isto é, redimensionar seus recursos de acordo com a demanda os usuários da aplicação. Após esse pico, as máquinas que foram instanciadas são normalmente desativadas, seus recursos liberados e o sistema retorna à capacidade anterior, evitando-se desperdício de recursos.

Embora interessante do ponto de vista de eficiência e custos, do ponto de vista forense a volatilidade da nuvem traz problemas em caso de ataques. Por exemplo, pode-se supor um cenário em que uma das instâncias de processamento virtuais criadas temporariamente seja alvo de ameaças que atuam diretamente na sua memória, sem deixar rastros no armazenamento. (e.g., em arquivos de $\log$ ). Nesse caso, as evidências desse evento podem ser completamente perdidas após as instâncias em questão serem desativadas e terem seus recursos liberados. Essa dificuldade é ainda agravada por aspectos como multi-inquilinato e multi-jurisdição, típicas de soluções em nuvem pública ou híbrida (KEYUN et al., 2011). Especificamente, o multi-inquilinato dificulta a obtenção do hardware que executa as aplicações de interesse. Afinal, como este é compartilhado por vários usuários, removê-los para análise poderia levar a uma violação de 
privacidade dos usuários não relacionados à investigação. Já a natureza distribuída da nuvem pode levar à alocação de informações relevantes em vários países, dificultando a sua obtenção, em especial quando não existem acordos de cooperação entre as entidades envolvidas (DYKSTRA; SHERMAN, 2012). Combinadas, tais características limitam a coleta de evidências com a credibilidade necessária para que elas possam ser aceitas em processos legais (RAHMAN; KHAN, 2015), que exigem o respeito à privacidade, à jurisdição e à cadeia de custódia, bem como a reprodutibilidade do processo de coleta.

\subsection{Motivação}

Embora existam soluções na literatura que abordam a coleta de informações de nuvem com o propósito de análise forense, a grande maioria delas aborda a coleta, o transporte e o armazenamento de forma isolada. Por exemplo, trabalhos como (DYKSTRA; SHERMAN, 2013) e (REICHERT; RICHARDS; YOSHIGOE, 2015) tratam de fatores como multi-inquilinato e multi-jurisdição, discutindo formas de coleta e preservação da evidência fora da nuvem. Já estudos como (GEORGE; VENTER; THOMAS, 2012) se concentram na análise forense para a coleta de evidência de máquinas virtuais em tempo de execução, enquanto trabalhos como (SANG, 2013) abordam processos de garantia da cadeia de custódia em ambientes de nuvem para transporte da evidência. Por outro lado, não foram identificadas na literatura propostas que (1) descrevam como o dado é coletado e armazenado observando a cadeia de custódia, e (2) visem garantir que, mesmo que um recurso virtualizado (e.g., uma máquina virtual ou contêiner) seja desalocado, haja condições de se reproduzir o processo de coleta de evidências. 


\subsection{Objetivos}

O presente trabalho visa suplantar as limitações identificadas na literatura com relação à capacidade de coleta de evidências de aplicações em nuvem. Mais precisamente, por meio de uma proposta que tem como focos (1) a reprodutibilidade do processo de coleta, (2) o estabelecimento de um vínculo entre a evidência coletada e sua origem, (3) a preservação da jurisdição e da privacidade dos não envolvidos na investigação e (4) a garantia de custódia da evidência. Desta forma, a solução buscada deve prover uma forma de obter dados relevantes para investigações ao mesmo tempo que permita transportar e armazenar tais dados preservando sua credibilidade. Para isso, a proposta supõe que o sistema sendo monitorado é executado dentro de um ambiente virtualizado em nuvem sob o modelo de comercialização de Infraestrutura como serviço ( Infrastructure as a Service - IaaS ). A presente proposta tem como foco prover uma solução técnica que atenda as necessidades jurídicas presentes hoje. Não faz parte dos objetivos deste trabalho propor alterações na legislação ou nos procedimentos legais vigentes. Sendo assim, limites impostos por leis e magistrados para coleta de evidência em seus locais de origem ainda devem ser respeitadas.

\subsection{Justificativa}

O crescente volume de informações que as soluções em nuvem armazenam e trafegam atualmente, bem como os aspectos de multi-inquilinato e a multi-jurisdição dos provedores de nuvem, estão entre os principais obstáculos enfrentados pelos investigadores forenses. (QUICK; CHOO, 2014) (KEYUN et al., 2011). Desta forma, a criação de soluções que permitam melhorar o processo de investigação forense nesse cenário tem relevância não apenas teórica, mas também prática.

Ao mesmo tempo, virtualização tem sido amplamente adotada por empresas das mais diversas áreas. Segundo o "State of the Cloud Report", relatório produzido pela 
empresa Right Scale (Right Scale, 2018), 96\% das organizações entrevistadas estão utilizando ou experimentando soluções em nuvem no modelo IaaS ( Infrastructure as a Service - Infraestrutura como um Serviço ). Embora a virtualização de recursos na nuvem seja tradicionalmente feita por meio de máquinas virtuais, tem ganhado importância também a tecnologia de contêineres (Diamant, 2019), uma forma de virtualização bastante leve e flexível. De fato, conforme o "Container Market Adoption Survey 2018" (Portworx, 2018), realizado com 519 empresas que têm desenvolvimento de software como sua atividade fim ou como suporte à atividade fim, 83,5\% dos respondentes utilizam contêineres em ambiente produtivo em suas arquiteturas de microsserviços em nuvem.

Por fim, gestão de incidentes, que cada vez mais compartilha processos em comum com forense digital principalmente na fase de detecção e análise, pode se beneficiar de uma solução de coleta e preservação de evidências. Ter uma solução que esteja pronta na fase de preparação ao incidente e seja capaz de preservar as evidências para a fase de pós-incidente, permite que na fase de detecção e análise não seja preciso se preocupar com perda parcial ou total de evidências.

Essa tendência motiva a construção de soluções que levem em consideração as particularidades inerentes aos recursos disponíveis em nuvens computacionais.

\subsection{Método}

Este trabalho segue o método hipotético-dedutivo que utiliza o conhecimento disponível na literatura para definir um problema de pesquisa e propor uma solução para o mesmo. Tal solução é então implementada como um protótipo para que seja avaliado e testado.

A primeira fase deste trabalho consistiu na avaliação da literatura para identificar os desafios da forense digital buscando lacunas no estado da arte relacionadas a 
abordagem destes desafios em um ambiente de infraestrutura em nuvem.

A segunda fase foi voltado a identificação de formas para solucionar os desafios levantados na fase anterior levando à especificação de uma solução de coleta, transporte e armazenamento para evidências coletadas de nuvem.

Finalmente, a terceira fase consistiu no desenvolvimento de um protótipo, permitindo que a proposta seja avaliada em um ambiente controlado.

\subsection{Organização do documento}

O restante deste documento está organizado conforme os seguintes capítulos.

O Capítulo 2 apresenta o ambiente em que este trabalho está inserido, as tecnologias envolvidas e os desafios a serem superados.

O Capítulo 3 analisa os trabalhos relacionados a forense de memória em nuvem.

O Capítulo 4 apresenta as atividades realizadas como parte do trabalho de pesquisa aqui apresentado.

O Capítulo 5 apresenta as conclusões e recomendações para trabalhos futuros 


\section{FUNDAMENTAÇÃO TEÓRICA}

Desde 2001, diversos modelos para a condução de investigação digital foram propostos. No First Digital Forensic Research Workshop foi definido o primeiro modelo de processo investigativo genérico para atender às investigações envolvendo sistemas digitais. Em seguida foi proposto o Abstract Digital Forensic Model, mais detalhado que o modelo genérico anterior e o Integrated Digital Investigation Process, baseado em teoria criminal e investigações não digitais do passado. Finalmente em 2003, Carrier e Stafford propõem a última iteração na evolução do processo forense digital, o Enhanced Digital Investigation Process Model (SIMOU et al., 2014). Entretanto, como tais modelos de investigação foram desenvolvidos antes da aparição de tecnologias de computação em nuvem, muitos partem do pressuposto que o investigador tem acesso e controle sobre o sistema sob investigação (GRISPOS; STORER; GLISSON, 2012). Novas pesquisas são necessárias para que a forense digital aborde apropriadamente as soluções em nuvem e suas particularidades.

Neste capítulo, são discutidos os principais conceitos que permeiam esse cenário. Especificamente, após uma discussão geral sobre computação em nuvem e suas particularidades, são discutidas os características esperadas de um processo de forense digital robusto e sua interseção com gestão de incidentes. 


\subsection{Nuvens computacionais e contêineres}

Uma nuvem computacional é um modelo de infraestrutura no qual recursos compartilhados em quantidade configurável, acessíveis via rede, são alocados e desalocados com esforço mínimo de gerenciamento por parte de um provedor de serviços. Existem três modelos principais de comercialização de uso da nuvem (MELL; GRANCE, 2011):

- Software como serviço ( Software as a Service - SaaS ): No qual se provê o software que será utilizado; nesse caso, os clientes do serviço são os usuários finais do software.

- Plataforma como serviço ( Platform as a Service - PaaS ): No qual se provê o ambiente para o desenvolvimento, teste e execução do software; nesse caso, os clientes do serviço são desenvolvedores de aplicações.

- Infraestrutura como serviço ( Infrastructure as a Service - IaaS ): No qual são fornecidos recursos computacionais básicos, como processamento, memória e redes, em geral de forma virtualizada.

O tipo de serviço de nuvem mais pertinente para este trabalho é o IaaS, uma solução muito usada atualmente pela sua capacidade de prover recursos sob demanda de forma auto-escalável. Nesse cenário, o uso intenso de tecnologias de virtualização costuma levar a recursos altamente voláteis, que são alocados e desalocados a qualquer momento pelo orquestrador da nuvem para suprir eventuais aumentos e reduções de demanda. É possível até mesmo construir scripts para a automatizar a construção da arquitetura desejada, permitindo a instanciação e interconexão de máquinas adequadas para a atividade fim do sistema. Esses scripts, escritos em linguagem específica como Puppet (Puppet, 2018), Chef (Chef, 2018) ou Vagrant (Vagrant, 2018), podem conter instruções de como distribuir o tráfego de rede entre as diferentes instâncias de com- 
putação ou armazenamento. Em suma, o modelo IaaS também permite controle direto nos elementos de infraestrutura.

Nos modelos SaaS e PaaS, o usuário não controla nem gerencia os elementos mais básicos de infraestrutura como armazenamento, sistema operacional e rede dos componentes de software oferecidos. Entre as vantagens de sua utilização, podem ser citadas a capacidade de usar os recursos de nuvem de uma forma mais eficiente, levar a uma menor necessidade de intervenção humana, e prover maior resiliência a variações de demanda do sistema (MELL; GRANCE, 2011). Como os detalhes da implementação destes serviços nos provedores de nuvem pública nem sempre são disponíveis, o presente trabalho não abordará os modelos PaaS e SaaS.

Uma tecnologia de virtualização possível para cenários de nuvem, e cuja utilização vem crescendo nos últimos anos, são os chamados contêineres (BERNSTEIN, 2014). Basicamente, um contêiner é um método de virtualização do sistema operacional que permite executar uma aplicação, bem como suas dependências, em um processo no qual recursos como disco, memória e rede permanecem isolados. Diferente das máquinas virtuais, a virtualização com contêineres é feita no nível do sistema operacional (SO) nativo. Como resultado, tem-se uma implementação de virtualização na qual eliminam-se camadas entre o aplicativo executado e o hardware físico, permitindo maior granularidade no controle sobre esses recursos e melhorando a eficiência da infraestrutura.

Uma implementação bastante utilizada para esse propósito são os Contêineres Linux ( LinuX Conteiners - LXC ) (LINUXCONTAINERS.ORG, 2015), que aproveitam-se de funcionalidades como cgroups, kernel namespacing e chroot do núcleo do Linux para auxiliar no gerenciamento e isolamento de recursos virtuais. Mais precisamente, a funcionalidade de cgroups ( Control Groups - Grupos de Controle ) presente no núcleo do Linux limita e isola o uso de recursos como CPU, memória e disco de um conjunto de processos, além de organizá-los de forma hierárquica. O 
trabalho nessa funcionalidade começou em 2006 na Google sob a denominação de process container. No final de 2007, seu nome foi alterado para control groups, e o resultado foi então adicionado à versão 2.6.24 do núcleo lançado em 2008 (Unix Man Pages, 2017a).

Já o Namespacing é uma funcionalidade do núcleo do Linux usada para isolar e virtualizar recursos do sistema operacional, como identificadores de processos, acessos à rede, comunicação inter-processos e sistema de arquivos. Namespacing envolve os recursos do sistema operacional em uma abstração que faz parecer aos processos de um mesmo namespace que estes tem sua própria instância isolada de um recurso global. Desta forma, essa é a principal funcionalidade por trás da implementação de Contêineres Linux (Unix Man Pages, 2017d).

Finalmente, chroot ( Change Root - Troque a raiz do sistema de arquivos ) é uma funcionalidade do núcleo do Linux usada para mudar o diretório root utilizado pelo processo que está chamando a função, bem como por todos os seus processos filhos. A chamada a chroot altera o processo de resolução de caminhos do sistema operacional para o processo que o chamou (Unix Man Pages, 2017b). Desta forma, pode-se instalar uma distribuição Linux secundária em uma pasta, ao invés de uma partição, e executar programas desta pasta sem perda significativa de desempenho.

\subsection{Forense digital e seus desafios}

A área de forense digital (também conhecida por forense computacional) refere-se a um conjunto de técnicas de coleta e análise da interação entre humanos e computadores de forma que suas conclusões sejam aceitas em um processo legal. Tal como a forense tradicional, a forense digital se baseia no princípio de Locard, estabelecido pelo médico francês Edmond Locard da seguinte forma: "Quando um indivíduo entra em contato com outro objeto ou indivíduo, este sempre deixa vestígio deste contato" (RA- 
MOS, 2011, p. 31). De forma similar, a forense digital tem por objetivo a investigação de evidências digitais da interação entre homem e máquina, de modo a reconstruir a cadeia de eventos passados para que suas conclusões sejam validadas por terceiros e sejam aceitas em um processo legal.

Nas próximas subseções são detalhados os principais desafios enfrentados pela forense digital quando aplicada a infraestruturas em nuvem.

\subsubsection{Admissibilidade da evidência em processo legal.}

O termo evidência é definido por (LUIS; SANCHEZ; GIOVA, 2016, p. 1) como qualquer item relevante e confiável, baseado em fatos ou dados, resultante de métodos apropriados e bem avaliados sob a perspectiva das ciências forenses que seja admitido por um juiz em um processo legal. Especificamente no contexto desta proposta, evidência é qualquer informação armazenada ou transmitida no formato digital, composta de campos magnéticos e pulsos eletrônicos que podem ser coletados e analisados por meio de ferramentas adequadas (RAMOS, 2011, p. 38).

O processo de análise forense no evento de um crime digital é descrito no Modelo Melhorado para Processo de Investigação Digital (Enhanced Digital Investigation Process Model - EDIPM) na forma de 4 fases (GRISPOS; STORER; GLISSON, 2012): identificar, preservar, examinar e apresentar. A fase mais pertinente a este trabalho é a de preservação da evidência, que deve ser conduzida de forma forensicamente aceitável. Ou seja, deve-se coletar as evidências de forma que estas sejam aceitas em um processo legal e não tenham sua credibilidade questionada no curso do mesmo como por exemplo alterações da evidência por processos investigativos. Alguns destes processos podem ser, a consolidação em um único local dos arquivos que compõem uma base de dados distribuída, a remoção da cifragem do conteúdo de um armazenamento ou a remoção da memória flash de um dispositivo para cópia de seu conteúdo (LUIS; SANCHEZ; GIOVA, 2016). 
Para atingir o objetivo de proteger a credibilidade da evidência, o principal passo é a garantia da cadeia de custódia da mesma. Cadeia de custódia é a documentação da história cronológica da evidência de modo a saber onde a evidência esteve e quem teve acesso a esta (RAMOS, 2011, p. 21). Uma cadeia de custódia idealmente deve tornar visível o estado da evidência antes, durante e após a interação com o processo de investigação (LUIS; SANCHEZ; GIOVA, 2016).

O passo seguinte é a garantia da autenticidade e da integridade da evidência. Autenticidade pode ser definida como "o processo pelo qual se pode garantir a autoria do documento eletrônico" (RAMOS, 2011, p. 21), ou seja, por meio do qual se não permite dúvida quanto à identificação do autor . Já a integridade pode ser definida como “o atestado da inteireza do documento eletrônico após sua transmissão, bem como apontar eventual alteração irregular de seu conteúdo" (RAMOS, 2011, p. 21). Caso haja dúvida acerca de um desses requisitos, uma perícia técnica pode ser convocada. Nesse caso, durante a perícia é analisado o autor da evidência, ou seja, verifica-se sua fonte e se a mesma não foi alterada no processo.

Em uma infraestrutura física, a coleta de evidências pode ser feita de forma relativamente simples, bastando-se remover o recurso físico, transportar este para um laboratório e lá analisar os dados. Para limitar a exposição da evidência a manipulações indevidas, esta pode ser mantida em uma sala-cofre, à qual o acesso é controlado. A reprodutibilidade do processo de coleta e a manutenção da integridade da evidência são, então, tarefas bem diretas.

Já em um cenário de computação em nuvem, especialmente as de infraestrutura auto-escalável, existe um conjunto de novos desafios. Primeiramente, em contraste com infraestruturas tradicionais, o recurso físico em princípio não pode ser removido: como os recursos são utilizados por outros usuários não relacionados à investigação, fazê-lo constituiria violação de privacidade tanto da pessoa física como da pessoa jurídica além de ser uma extrapolação dos limites de coleta concedidas pelo poder ju- 
diciário de uma região. A volatilidade dos recursos também torna a verificação do seu autor um processo mais complexo, pois o recurso que gera certa evidência pode deixar de existir algum tempo depois de fazê-lo (SIMOU et al., 2014). A integridade da evidência também acaba sendo uma tarefa não trivial, pois ela precisa ser coletada, transportada e armazenada, o que caracteriza a necessidade de preservação da cadeia de custódia. A violação de qualquer uma dessas características pode colocar em dúvida a credibilidade da evidência. Embora a admissibilidade da evidência em um processo legal seja uma decisão do juiz a credibilidade da mesma tem papel importante nesta decisão.

\subsubsection{Volume de dados para coleta}

O processo de coleta de evidências na forense digital herda suas práticas da forense tradicional, na qual isola-se cena do crime e coletam-se as evidências presentes. Transportando esse método para a forense digital, introduz-se a realização da cópia bit a bit da informação que se deseja analisar. No passado, com as soluções manipulando quantidades bem menores de memória, disco e tráfego, tal prática não era considerada muito problemática. Entretanto, acesso fácil e dinâmico a recursos de armazenamento e de processamento, como máquinas virtuais, balanceadores de carga e firewalls, aumentando a quantidade elementos geradores de evidência (WEN et al., 2013).

Nas atuais soluções, aplicações e arquiteturas em nuvem, o volume de dados é consideravelmente maior (QUICK; CHOO, 2014), (SIBIYA; VENTER; THOMAS, 2015). Esse problema é ilustrado em (QUICK; CHOO, 2014), na qual se discute uma investigação cuja quantidade de dados a serem analisados para fins de forense digital tomaria 6 meses. Encontrar uma forma de armazenar menos informações e, assim, tornar a fase de análise mais rápida e eficiente, é um passo importante para garantir a celeridade de investigações forenses. 


\subsubsection{Privacidade e jurisdição}

A prática de remoção de equipamentos para coleta de evidências, mencionada na Subseção 2.2.2, também traz consequências negativas do ponto de vista de privacidade. Mais precisamente, em soluções envolvendo infraestruturas físicas, tal prática não costuma trazer grandes problemas porque os objetos ou indivíduos sob investigação normalmente estão diretamente relacionados ao equipamento removido. Nas soluções em nuvem, entretanto, tal prática não é recomendada porque o recurso físico é compartilhado por vários usuários, inclusive indivíduos não envolvidos na investigação. Logo, remover tais recursos configuraria violação de privacidade (KEYUN et al., 2011). Como um complicador adicional, o fato de os dados potencialmente não estarem armazenados no mesmo território em que a investigação é realizada acaba demandando acordos de cooperação jurídica entre as partes, o que nem sempre é possível (SIMOU et al., 2014).

Embora privacidade e jurisdição sejam aspectos distintos e possuidores de suas particularidades, neste documento estes são discutidos em conjunto pois em busca de otimização de custos as empresas tendem a buscar regiões mais baratas e compartilhamento do recurso físico. Neste cenário, encontrar uma forma de coletar a evidência sem violar jurisdição e privacidade ganham importância.

\subsubsection{Coleta de evidências de memória volátil de máquinas em nu- vem}

A prática de armazenar histórico de tráfego de rede e alterações de dados armazenados em disco já é bem difundida na comunidade forense. Por outro lado, a memória volátil de computadores não costuma receber o mesmo tratamento: suas alterações quase nunca são armazenadas, seja por questões de desempenho ou por simples praticidade, dado a reduzida sobrevida dessas informações. Infelizmente, isso acaba dificultando a análise de uma classe específica de ataques, conhecidos como injeção de 
código em memória (CASE et al., 2014). Assim, quando usados contra uma arquitetura em nuvem, tais ataques não deixam rastros quando recursos de processamento virtuais são desativados e sua memória é liberada (VöMEL; STüTTGEN, 2013; CASE et al., 2014). Em particular, têm especial interesse quatro tipos particulares dessa família de ameaças (CASE et al., 2014):

- Injeção remota de bibliotecas: Um processo malicioso força o processo alvo a carregar uma biblioteca em seu espaço de memória. Como resultado, o código da biblioteca carregada executa com os mesmos privilégios do executável em que ela foi injetada. Tal estratégia, comumente usada para instalar códigos maliciosos, pode fazer com que uma biblioteca maliciosa armazenada no sistema seja distribuída por vários processos de uma mesma máquina, dificultando sua remoção (MILLER; TURKULAINEN, 2004).

- Inline Hooking: Um processo malicioso escreve código como uma sequência de bytes diretamente no espaço de memória de um processo alvo, e então força este último a executar o código injetado. O código pode ser, por exemplo, um shell script.

- Injeção reflexiva de biblioteca: Um processo malicioso acessa diretamente a memória do processo alvo, inserindo nela o código de uma biblioteca na forma de uma sequência de bytes, e então força o processo a executar essa biblioteca. Nessa forma de ataque, a biblioteca maliciosa não existe fisicamente; isso torna tal estratégia de injeção de código potencialmente mais atrativa, pois o carregamento da biblioteca não é registrado no sistema operacional (SO), dificultando a detecção do ataque (FEWER, 2008).

- Injeção de processo vazio: Um processo malicioso dispara uma instância de um processo legítimo no estado "suspenso"; a área do executável é então liberada e realocada com código malicioso. 


\subsection{Forense digital e gestão de incidentes}

Gestão de incidentes é uma estratégia para reduzir os riscos à confidencialidade, integridade e disponibilidade de ativos de uma organização, bem como minimizar sua perda. As fases relevantes de uma estratégia de gestão de incidentes são (Ab Rahman; CHOO, 2015), (CICHONSKI et al., 2012):

- Preparação: Onde se organiza o ambiente para minimizar impactos de um incidente, nesta fase também é definido o time de resposta a incidente que tem como responsabilidade determinar o que ocorreu e quais ações devem ser tomadas.

- Detecção: Tem como objetivo minimizar o risco das ameaças que não foram antecipadas. A fase de detecção começa quando alguma atividade suspeita é detectada por algum serviço automático como um sistema de detecção de ameaças ou por intervenção humana como o de um responsável pela análise de risco.

- Resposta ao incidente: Contém as fases de contenção, erradicação e recuperação. Não existe um procedimento que atenda a todas os cenários, os procedimentos são feitos de acordo com a natureza e as necessidades do negócio.

- Pós incidente: Última fase da gestão de incidentes, sua principal preocupação é coleta de informações das três fases anteriores para alimentar um processo de aprendizado visando evitar futuros incidentes semelhantes.

A gestão de incidentes tem o foco em conter falhas de segurança. Considerações como coleta de evidências costuma ser secundário (Ab Rahman; CHOO, 2015). A oportunidade de se aplicar processos de coleta forenses em gestão de incidente já foi levantado por (RAHMAN; CAHYANI; CHOO, 2016) uma vez que ambos compartilham de um ferramental em comum.

Ferramental e técnicas forenses estão se tornando úteis não só para geração de evidências para processos jurídicos mas também para ajudar na reconstrução de eventos 
em um incidente. Incorporar práticas forenses na estratégia de gestão de incidente, não só ajuda na geração das evidências necessárias para eventual processo jurídico como também ajuda a proteger as evidencias de dano como resultado das fase de resposta ao incidente onde o principal objetivo é a restauração do serviço. 


\section{REVISÃO DA LITERATURA}

Os principais aspectos relacionados ao tratamento de evidências para análise forense em nuvem são: coleta, transporte, armazenamento, garantia da cadeia de custódia e reprodutibilidade do processo de coleta. Este capítulo descreve o estado da arte e discute como a presente proposta se insere nesse contexto.

\subsection{Soluções para análise forense em nuvem}

Nesta seção são descritas algumas das principais propostas existentes para coleta de evidências forenses, fornecendo uma visão geral do estado da arte na área.

Apesar do crescimento das soluções baseadas em contêiner, as propostas encontradas na literatura até o presente momento estão focadas apenas em coleta de evidências de máquinas virtuais. A única proposta que trata de forense em contêiner é a (JIANG; SHENG, 2016), que é focada em PaaS e coleta de evidências presentes em armazenamento de contêiner, modelo que está fora do contexto deste trabalho.

\subsubsection{Modelo automático de aquisição de dados para fins forenses}

O modelo proposto por (REICHERT; RICHARDS; YOSHIGOE, 2015), ilustrado na Figura 1, é um processo de coleta de evidências integrado ao hipervisor e disparado por algum sistema de detecção de intrusão. A partir do momento em que uma ameaça é detectada, o modelo dita que sejam criados instantâneos (snapshots) das máquinas virtuais comprometidas. O intervalo de tempo em que os instantâneos de memória são 
gerados é configurável, e todos eles são armazenados em persistência. O modelo se preocupa em, de forma automatizada, excluir informações de clientes não relacionados à investigação e também em armazenar o restante em local seguro. A proposta não descreve os detalhes do armazenamento, embora afirma que isso deve ser feito de forma forensicamente aceitável.

Para agregar e analisar as evidências coletadas, o modelo faz uso do Resposta Rápida Google (Google Rapid Response - GRR), uma ferramenta de resposta a incidentes criado no projeto $20 \%$ na Google para facilitar análises forenses de forma remota (e.g., acesso de baixo nível ao armazenamento e à memória das máquinas analisadas) (GOOGLE, 2013). O tratamento de evidências usa um motor de regras baseado em um conjunto de descrições de ameaças conhecidas, as quais são armazenadas em um banco de dados. Caso alguma evidência coletada coincida com ameaças armazenadas, esse motor alerta um usuário humano para uma avaliação mais detalhada (REICHERT; RICHARDS; YOSHIGOE, 2015). A característica deste modelo que mais contribui para a forense digital é a automação do processo de coleta, já que, ao menos em parte, ele dispensa intervenção humana.

\subsubsection{Introspecção em máquina virtual}

A proposta de (POISEL; MALZER; TJOA, 2013) é baseada na técnica de Introspecção em Máquina Virtual (Virtual Machine Introspection - VMI) para coleta de memória volátil. Essa técnica se apoia no fato de que o hipervisor mapeia os recursos alocados para máquinas virtuais nos recursos físicos correspondentes da máquina hospedeira. Este mapeamento é usado para permitir que a memória volátil copiada da máquina virtual seja reconstruída em uma máquina física, para análise posterior. A proposta realiza coleta contínua de instantâneos de memória durante o funcionamento do sistema, sem distinção do que aconteceu antes ou depois do fato de interesse, e todos os instantâneos de memória são armazenados para análise. Visando eliminar a 
Figura 1: Modelo Automático de Aquisição de Dados Forenses

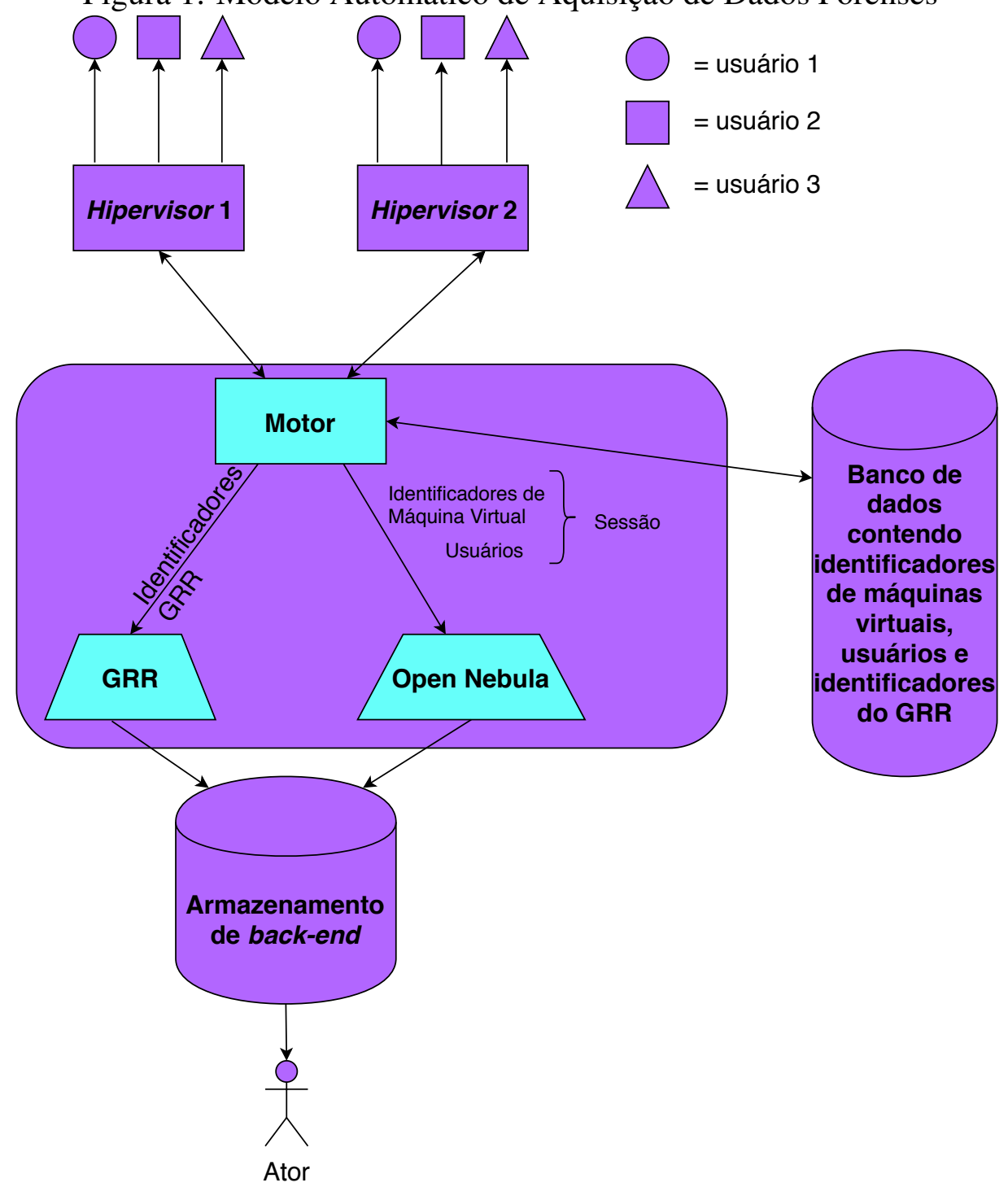

Adaptado de (REICHERT; RICHARDS; YOSHIGOE, 2015)

chance de inconsistências no instantâneo de memória volátil, a máquina virtual tem sua execução suspensa durante o processo de extração.

Em (POISEL; MALZER; TJOA, 2013), no capítulo 3.1, o próprio autor menciona que a necessidade de tradução de endereços de memória da máquina virtual em endereços de memória da máquina física hospedeira dificulta a utilização da técnica em larga escala. Como essa tradução depende de conhecimento do que está sendo executado na máquina virtual, uma solução baseada em VMI não é completamente portável, 
sendo necessárias adequações para diferentes clientes. Além disso, esta tradução de endereços pode ser computacionalmente custosa.

\subsubsection{Virtuoso}

Também na vertente de introspecção de máquina virtual, (DOLAN-GAVITT et al., 2011) propõe o Virtuoso, um arcabouço de coleta de informações de processos específicos em uma máquina virtual. $\mathrm{O}$ arcabouço funciona em três fases. A primeira realiza um estudo em uma máquina virtual de testes, mapeando o conjunto de instruções executado pelo processo do qual se deseja coletar dados de memória. O estudo é realizado no Ambientes de Treino e o Leitor de Instruções coleta e armazena as instruções geradas pelo processo alvo da análise e os armazena no banco de dados de Instruções Armazenadas. Na segunda fase, o Analisador de Instruções cria um executável a partir do conjunto de instruções coletado na fase anterior. Estas instruções precisam ter suas referências de memória traduzidas para que seja possível executá-las fora do ambiente original, o que ocorre no Tradutor de Instruções. Com o executável, a terceira fase usa um Ambiente Virtual Seguro na máquina hospedeira capaz de acessar os endereços de memória do Ambiente Virtual Não Confiável, tornando possível coletar instantâneos de memória do processo em execução. A Figura 2 ilustra o funcionamento desse arcabouço.

A característica deste modelo que mais contribui para a forense digital é a capacidade de coletar instantâneos de memória de um processo específico e reproduzi-lo em um ambiente confiável. Entretanto sua atuação se dá apenas após o evento que se deseja avaliar forensicamente.

\subsubsection{Abordagem baseada em logs}

O arcabouço proposto por (SANG, 2013) é um sistema que funciona em parceria com o provedor de nuvem: o provedor último envia informações ao arcabouço, que 
Figura 2: Virtuoso

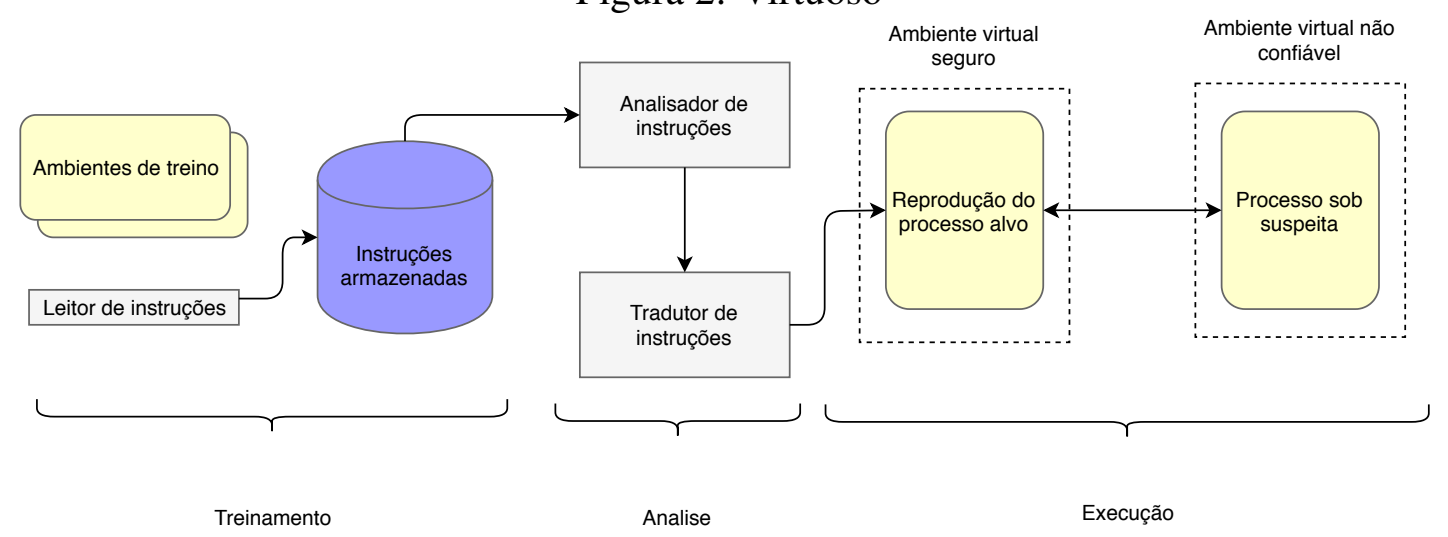

Adaptado de (DOLAN-GAVITT et al., 2011)

por sua vez as armazena em um local adequado, de forma centralizada. O conjunto de informações armazenadas é negociado antecipadamente com o provedor de nuvem, indo desde instantâneos de memória volátil até pacotes trafegados nas interfaces de rede da máquina virtual. $\mathrm{O}$ arcabouço coleta informações continuamente e usa cálculo de hash das evidências enviadas pelo provedor de nuvem para garantir que elas não foram alteradas durante o transporte. A Figura 3 ilustra o funcionamento da solução, focando em um caso específico de log de rede, de modo similar ao descrito em (SANG, 2013).

Assim como as propostas anteriores, o arcabouço em questão também não faz distinção do que aconteceu antes ou depois do fato de interesse, mas coleta constantemente informações da máquina virtual. Outra potencial limitação é que o arcabouço depende da cooperação do provedor de nuvem. Tal dependência é uma estratégia considerada fraca pela comunidade forense (ALQAHTANY et al., 2015), pois a prioridade do Provedor de Serviços de Nuvem (Cloud Service Provider - CSP) é a de garantir a disponibilidade do serviço, não de coletar evidências. 
Figura 3: A Log Based Approach Model

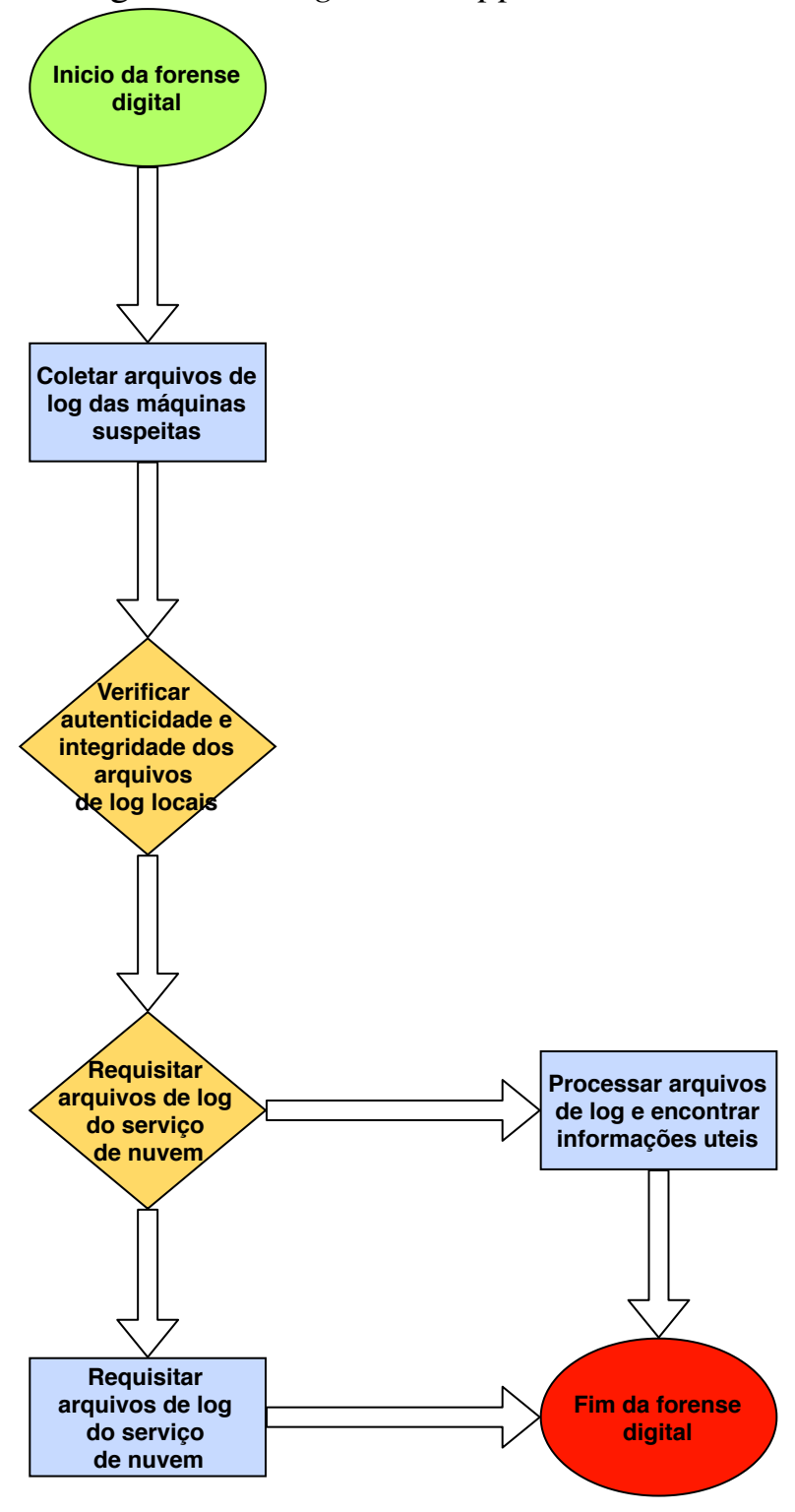

Adaptado de (SANG, 2013)

\subsubsection{Abordagem baseada em backups}

O trabalho descrito em (DEZFOULI et al., 2012) é voltado a dispositivos móveis e tem como principal característica a preocupação com as limitações de armazenamento do dispositivo. Por essa razão, o processo de coleta de instantâneos de memória volátil e armazena separadamente as informações de cada processo que está ativo de modo a permitir um gerenciamento adequado do espaço de armazenamento. A solução 
também se preocupa em descartar informações de processos que foram terminados e removidos da memória, além de buscar o uso consciente do espaço de armazenamento disponível no dispositivo. A Figura 4 mostra, em alto nível, a forma como o armazenamento de evidências é gerenciado.

Como em diversas outras propostas, processo de coleta de informações de memória volátil em (DEZFOULI et al., 2012) é executado continuamente, independente de eventos de interesse (e.g., detecção de ameaças). Um outro fator que conta como desvantagem nesta proposta é o processo não armazenar histórico das coletas anteriores, como é possível ver na Figura 4. A coleta anterior é substituída pela nova.

Figura 4: Backup Approach Model

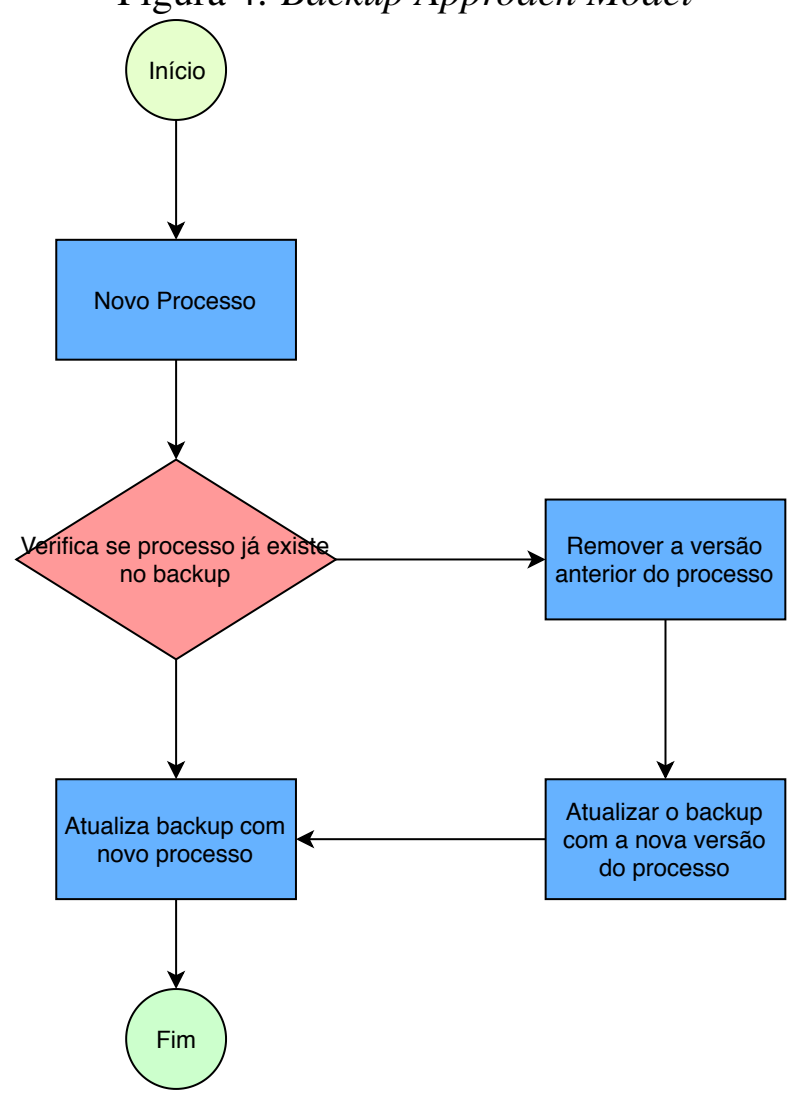

Adaptado de (DEZFOULI et al., 2012) 


\subsubsection{Arcabouço forense para OpenStack}

As Ferramentas Forenses para Arcabouço OpenStack (FoRensic OpenStack Tools - FROST), proposta por (DYKSTRA; SHERMAN, 2013), consiste em um conjunto de bibliotecas integradas ao OpenStack, um dos arcabouços de gerenciamento de infraestruturas virtualizadas bastante difundido (STACK, 2018). Por meio dessa integração, o FROST expõe um conjunto de APIs que podem ser usadas por aplicações de coleta de evidências forenses. Essas APIs dão acesso a recursos da máquina virtual administrada, tais como disco, $\log s$ de tráfego de rede e memória volátil. A proposta descreve apenas o arcabouço, deixando a critério do usuário detalhes como periodicidade e tamanho da coleta, bem como a forma de transporte da evidência e onde ela é armazenada.

A Figura 5 ilustra a integração entre FROST e o arcabouço OpenStack. Nela é possível ver os dois pontos desta integração. O primeiro em sua camada de interface de administração web, através da API de Computação (Compute API) onde o usuário pode acionar a coleta de artefatos para análise. A segunda ocorre em seu núcleo, adiciona novas chamadas a API Nova (Nova API) do OpenStack para viabilizar a coleta de informações da máquina virtual e também integra com os processos de rede para extrair logs de tráfego da rede.

O autor declara que FROST segue as práticas definidas no Grupo de Pesquisa Cientifica Em Evidência Digital (Scientific Working Group on Digital Evidence - SWGDE) e do Manual de Busca e Apreensão do Departamento de Justiça Norte-Americano (DYKSTRA; SHERMAN, 2013). De todas as propostas avaliadas, a FROST é a única que mostra preocupação com adequação a questões legais como cadeia de custódia e integridade da evidência. 
Figura 5: FoRensic OpenStack Tools

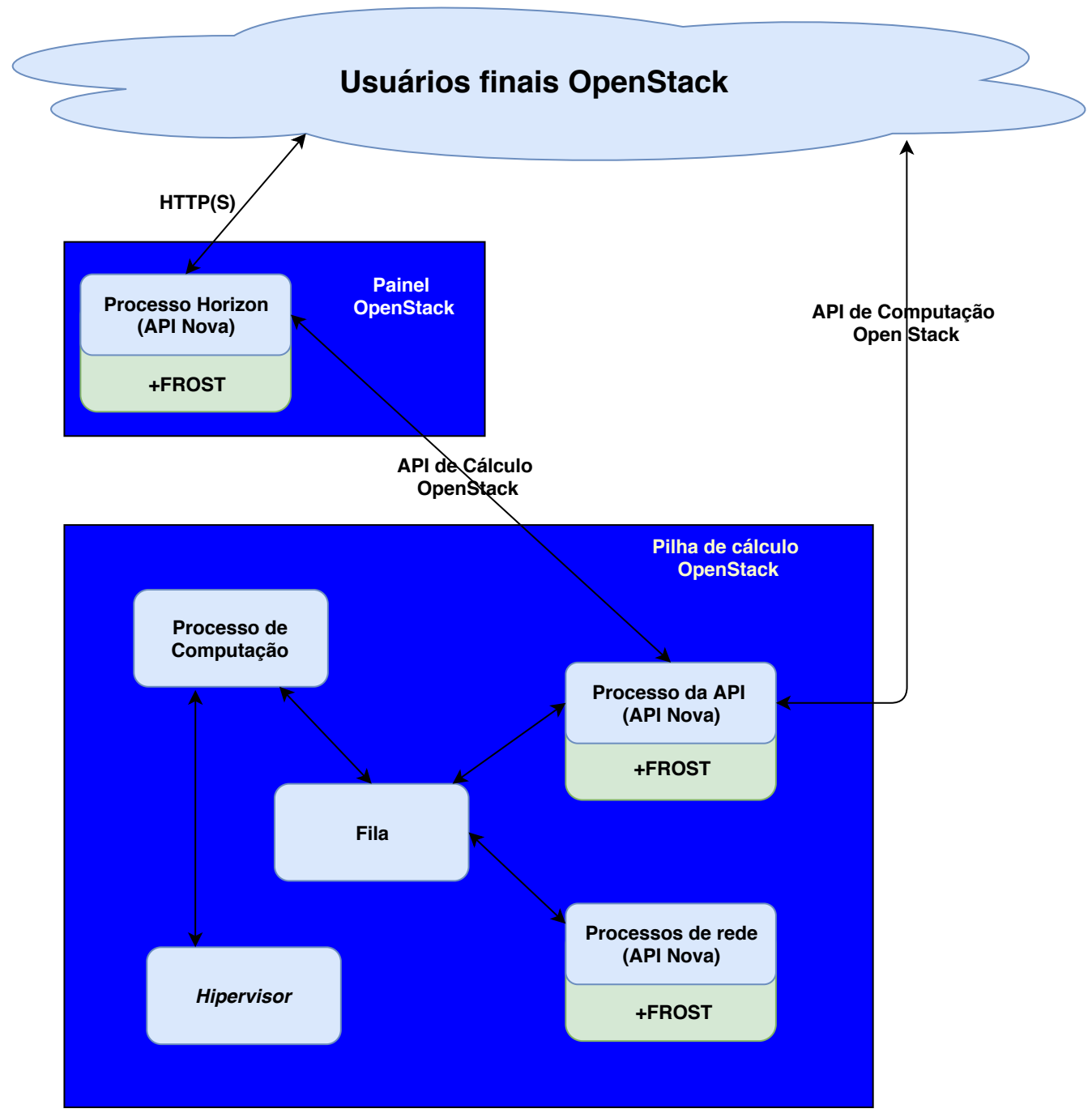

Adaptado de (DYKSTRA; SHERMAN, 2013)

\subsubsection{Forense como serviço}

O trabalho descrito em (GEORGE; VENTER; THOMAS, 2012) se concentra em monitoramento de rede, operando em uma arquitetura de Forense Como Serviço.Conforme ilustrado na Figura 6, a arquitetura da solução consiste em um conjunto de ferramentas com capacidade de descobrir automaticamente as interfaces sob monitoramento, além de coletar evidências de tais máquinas e armazená-las.

O processo de autodescoberta e associação das evidências com usuários de rede é 
realizado por um motor baseado em ontologias armazenadas em um banco de dados próprio. As ontologias são utilizadas para determinar a associação entre as evidências coletadas e os usuários ou artefatos que as geraram. O Minerador de dados implementa um algoritmo de descoberta de arquivos de $\log$ de artefatos de rede definidos como relevantes. O Monitor de rede é responsável por interceptar o tráfego entre as partes consideradas suspeitas e por fim, a Monitoração do Sistema em Tempo Real captura informações específicas do sistema em execução como instantâneos dos processos sob investigação. Entretanto, a proposta se concentra apenas no processo de coleta, enquanto a descrição dos mecanismos de armazenamento e transporte não é detalhada.

\subsubsection{Abordagem de indexação de dados coletados para fins foren- ses}

Na mesma vertente da solução de forense como serviço descrita na Subseção 3.1.7, (LEE; UN, 2012) trata o problema de grande volume de dados coletados por meio de um serviço de coleta e indexação de evidências. O serviço espera receber dados da execução do comando unix DD (Unix Man Pages, 2017c) nas máquinas alvo, nas quais, apoiado em processos de Extrair, Transformar e Carregar (Extract, Transform and Load - ETL) e MapReduce (Andrade, Tiago, 2008), os dados são disponibilizados para consulta pelos investigadores. A coleta ocorre continuamente, em intervalos de tempo configuráveis.

A Figura 7 mostra a arquitetura da solução. Um Armazenamento Acessado via Rede (Network Accessed Storage - NAS) é usado para armazenar as evidências coletadas. Antes da análise dos dados pelos processos de MapReduce é necessário executar o processo de ETL para adequar a informação a necessidade específica da investigação. Esta fase ocorre nos Nós Filtrando. Em seguida a informação é submetida ao processo de MapReduce e armazenado em um HBase (HBase, 2018). O Nó Mestre tem o papel 
Figura 6: Digital Forensic Framework for Cloud Environment

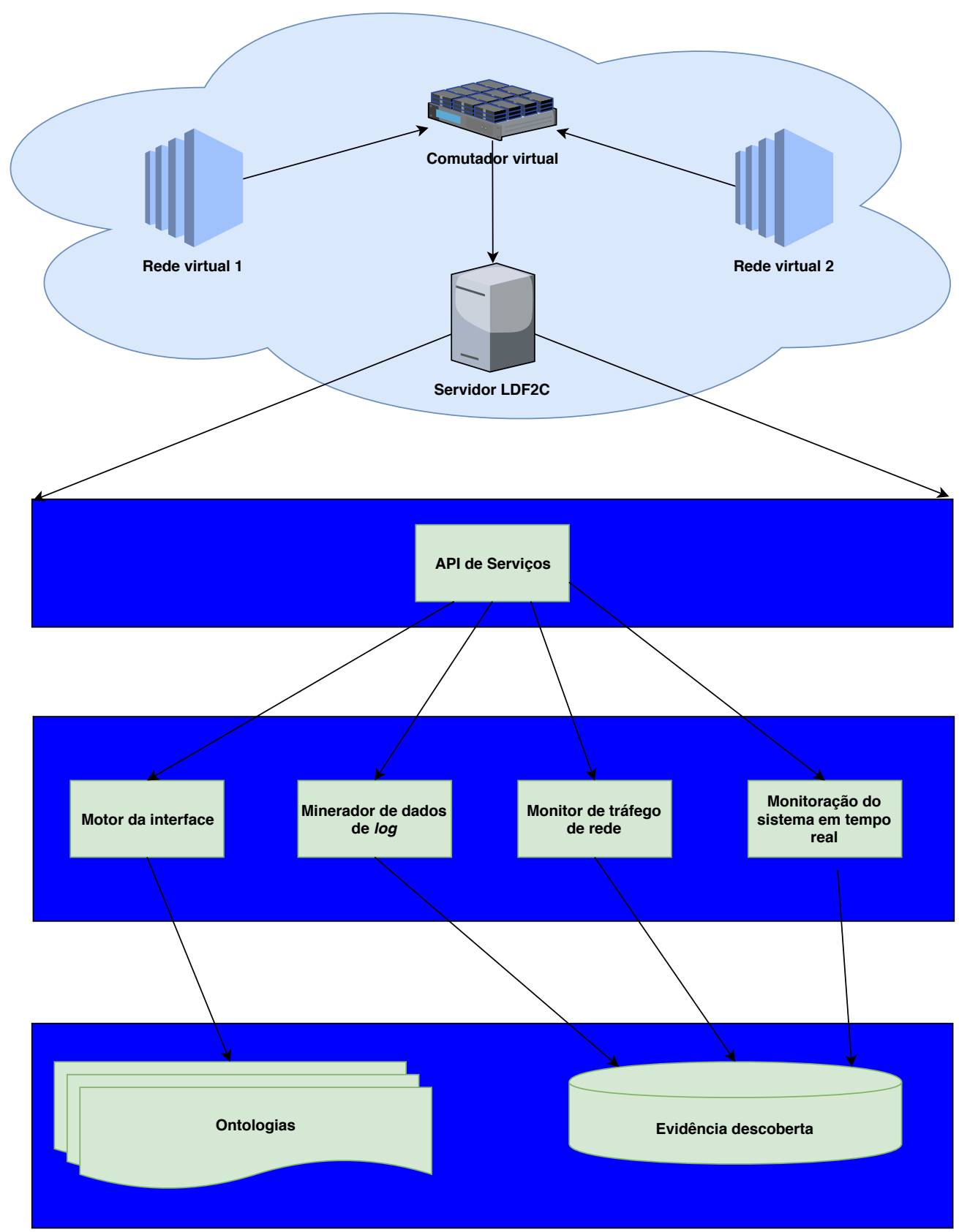

Adaptado de (GEORGE; VENTER; THOMAS, 2012)

de orquestrador enviando os comandos de indexação dos dados coletados e recebendo as requisições de busca dos usuários via seu Servidor Web.

Embora interessante, a solução não deixa claro a localização do armazenamento dos dados coletados, nem quem é responsável pela infraestrutura de armazenamento. 
Também não é discutido como os dados são transportados até o ponto de armazenamento, nem como garantir que esses dados não sejam alteramos no processo.

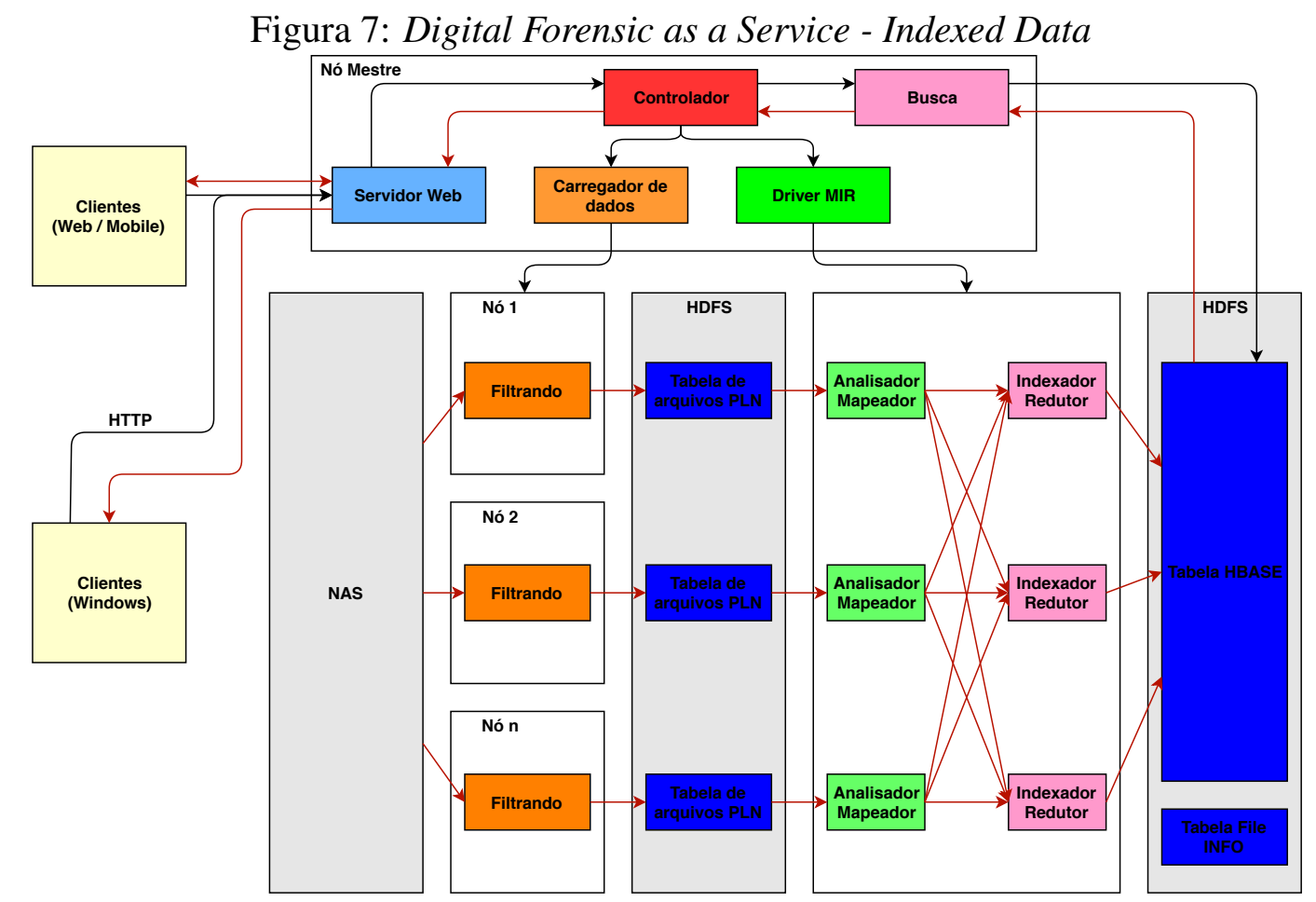

Adaptado de (LEE; UN, 2012)

\subsection{Aspectos relacionados a coleta de evidência}

Para uma discussão mais estruturada, nas próximas subseções os trabalhos mencionados na Subseção 3.1.2 são agrupados e avaliados com base nos diferentes aspectos que abordam.

\subsubsection{Acessar e coletar as informações de memória das máquinas virtuais em nuvem}

Diversos trabalhos de análise forense na nuvem se concentram na coleta de dados "após o fato", ou seja, após a intrusão ser detectada (REICHERT; RICHARDS; YOSHIGOE, 2015; POISEL; MALZER; TJOA, 2013; DYKSTRA; SHERMAN, 2013; GEORGE; VENTER; THOMAS, 2012; SANG, 2013). Os processos de coleta 
descritos nesses trabalhos podem ser iniciados de forma manual ou automaticamente, via integração com um mecanismo de detecção de intrusão. No caso específico de memória volátil, tal forma de coleta não consegue descrever como era a memória antes da intrusão, pois o processo só é acionado depois da detecção do ataque. Tal limitação pode trazer prejuízos à investigação, dado que algumas análises dependem exatamente da capacidade de se comparar dois momentos da memória (CASE et al., 2014). Entre os trabalhos estudados, a única proposta encontrada que leva tal necessidade em consideração é (DEZFOULI et al., 2012), que propõe que o dado seja armazenado no próprio equipamento sob análise. Infelizmente, entretanto, a aplicação de tal abordagem no cenário em nuvem é pouco viável, pois pode levar à perda de informações importantes caso a máquina virtual ou contêiner seja desativada, tendo seus recursos liberados.

Existem ainda trabalhos voltados à coleta de informações durante a execução do sistema, nos quais os dados são constantemente coletados sem distinção do que aconteceu antes ou depois do fato de interesse. Esse é o caso de trabalhos como (POISEL; MALZER; TJOA, 2013; DYKSTRA; SHERMAN, 2013; SANG, 2013; DOLANGAVITT et al., 2011), que adotam a estratégia de isolar e parar a máquina virtual para em seguida realizar o processo de coleta. Embora interessantes, as abordagens descritas nesses trabalhos podem levar a um elevado volume de dados coletados. Além disso, elas não tratam o cenário em que é necessário coletar evidências quando são liberados os recursos virtuais que as contêm.

\subsubsection{Capacidade de reproduzir o processo e obter os mesmos re- sultados}

Se, durante uma análise forense, analistas diferentes obtêm resultados distintos ao executar o mesmo procedimento de coleta, a evidência gerada não tem credibilidade, inviabilizando seu uso em um processo legal. Por essa razão, a reprodutibilidade 
do processo de coleta é uma parte importante da geração de evidências para análise forense. Infelizmente, entretanto, nenhuma das propostas encontradas na literatura atualmente permite tal reprodutibilidade em cenários de nuvem, em que máquinas virtuais ou contêineres são desativados e seus recursos físicos liberados. Afinal, todas elas dependem da existência do recurso virtual para a repetição do processo de coleta.

\subsubsection{Não violar privacidade ou jurisdição das partes não envolvi- das na investigação}

Em um ambiente de nuvem pública, remover o hardware para análise posterior pode levar à violação de privacidade de usuários pessoa física e jurídica. A razão é que o multi-inquilinato desse cenário faz com que uma mesma máquina física guarde informações de diversos clientes, alguns dos quais podem não estar envolvidos na investigação em curso. Diversos trabalhos na literatura tratam esse problema adequadamente, por meio de duas estratégias principais: a primeira, adotada em (REICHERT; RICHARDS; YOSHIGOE, 2015; GEORGE; VENTER; THOMAS, 2012; POISEL; MALZER; TJOA, 2013; DYKSTRA; SHERMAN, 2013; LEE; UN, 2012), consiste em coletar dados pertinentes à investigação e armazená-los fora da nuvem; a segunda, empregada em (SANG, 2013) e que constitui um caso específico de (GEORGE; VENTER; THOMAS, 2012), depende da cooperação do provedor de serviços de nuvem para conseguir as informações necessárias à investigação. Depender do provedor de serviços de nuvem é uma estratégia pouco recomendada (ALQAHTANY et al., 2015), entretanto, pois (1) o volume de dados de usuários pode forçar os provedores a limitar o tamanho dos logs armazenados, e (2) caso ocorra uma indisponibilidade causada por um ataque, o objetivo do provedor será o de restabelecer o serviço, não necessariamente o de preservar evidências. 


\subsubsection{Garantir a cadeia de custódia da evidência}

Dentre os trabalhos analisados, apenas (SANG, 2013) aborda a questão da garantia da cadeia de custódia. Especificamente, o trabalho emprega hashes para verificar a integridade da evidência, permitindo a detecção de alterações. Uma limitação desse trabalho, entretanto, é que ele não deixa explícitos os mecanismos que poderiam ser utilizados para impedir acesso não autorizado (e, assim, potencial alteração) aos próprios hashes. As propostas dos outros autores concentram-se apenas no aspecto técnico da coleta, sem discutir detalhadamente garantia de custódia. Em geral, os trabalhos apenas mencionam que as evidências devem ser coletadas de forma forensicamente aceitável.

\subsection{Resumo}

A Tabela 1 mostra um comparativo das soluções estudadas, considerando os aspectos discutidos nesta seção, posicionando as contribuições da proposta apresentada neste trabalho. 
Tabela 1: Comparativo de soluções de coleta de informações de memória de máquinas em nuvem para análise forense

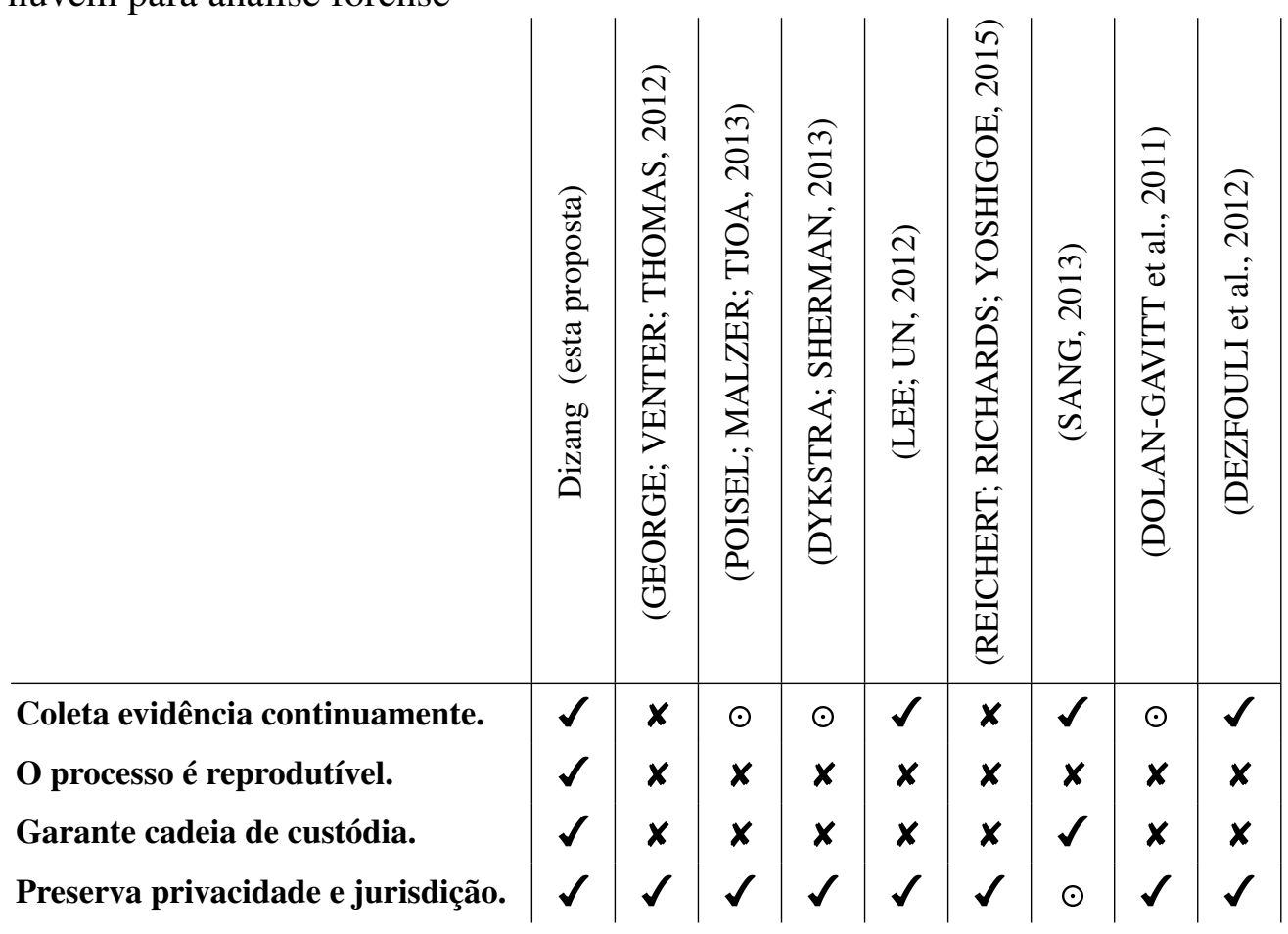

$\boldsymbol{V}$ - atende; $\boldsymbol{X}$ - não atende; $\odot$ - atende parcialmente 


\section{PROPOSTA DE PROJETO: DIZANG}

A presente proposta tem como objetivo principal coletar memória de recursos computacionais virtuais em arquitetura volátil de modo a conseguir: (1) identificar a fonte da evidência, mesmo se o recurso virtual não existir mais e assim conseguir reproduzir o processo de coleta; (2) descrever o sistema antes e depois do incidente mantendo sob controle a quantidade de dados coletados; (3) transportar e armazenar a memória coletada de uma forma que garanta a cadeia de custódia; e (4) não violar a jurisdição e a privacidade de outros usuários que porventura tenham recursos alocados no mesmo servidor físico. A solução aqui apresentada, denominada Dizang, é descrita em detalhes nas próximas subseções.

\subsection{Identificação da origem}

Em sistemas computacionais executados sobre uma infraestrutura física (i.e., não virtualizada), pode-se fazer uma associação direta entre um recurso qualquer e sua origem correspondente, seja este recurso uma informação da memória, imagem de disco ou pacotes trafegando na rede. Já em sistemas construídos sobre uma infraestrutura virtual, em especial quando ela é auto-escalável, os recursos computacionais são altamente voláteis e, portanto, podem ser desalocados a qualquer momento. Este fato torna difícil a associação de uma informação gerada por esta infraestrutura com sua origem.

Para conseguir correlacionar uma evidência a sua origem volátil, é necessário uti- 
lizar outro elemento em que persista a relação fonte-evidência. O presente trabalho propõe que isto seja feito por meio de cálculo de hash do recurso em nuvem que produziu a evidência. O hash de um recurso em nuvem permite identificar univocamente a fonte de uma evidência. Em arquiteturas que utilizam contêiner por exemplo, é possível identificar se a evidência veio do contêiner do motor de páginas dinâmicas (e.g., Apache), do contêiner da lógica de negócios (e.g., golang) ou do contêiner do banco de dados (e.g., Cassandra).

\subsection{Descrever o sistema antes e depois do incidente}

A cópia de memória não é uma atividade atômica, pois ela é executada em conjunto com outros processos. Portanto, caso um desses processos seja um código malicioso apagando traços de sua existência da memória do recurso, informações possivelmente importantes para a investigação podem acabar sendo perdidas. Com o objetivo de deixar o processo de cópia da memória mais atômico, a fim de evitar inconsistências na informação coletada (CASE et al., 2014), Dizang propõe que a execução do recurso em nuvem seja temporariamente suspenso para que seja realizada a cópia de sua memória. Essa técnica, que é semelhante àquela adotada em (RAFIQUE; KHAN, 2013) para VMs, produz um instantâneo da memória volátil do recurso; isso permite sua análise em um estado de repouso, ou seja, sem a necessidade de ter o recurso em execução. Ao realizar a coleta em intervalos de tempo adequados, é possível construir um histórico do estado da memória durante a execução no recurso.

A maioria das técnicas forenses mais usadas atualmente são voltadas à obtenção da informação em sua totalidade. Isso comumente é feito via cópia bit a bit ou por meio da obtenção do hardware físico (SIMOU et al., 2014) (BEM et al., 2008). Embora tais técnicas possam parecer interessantes à primeira vista, estas muitas vezes acabam sendo responsáveis por um problema: o crescente volume de informações que os investigadores precisam analisar (QUICK; CHOO, 2014). Para mitigar essa dificul- 
Figura 8: Janela deslizante de coleta de evidência

Operação normal

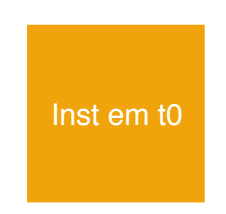

Instantâneo de memória a ser descartado

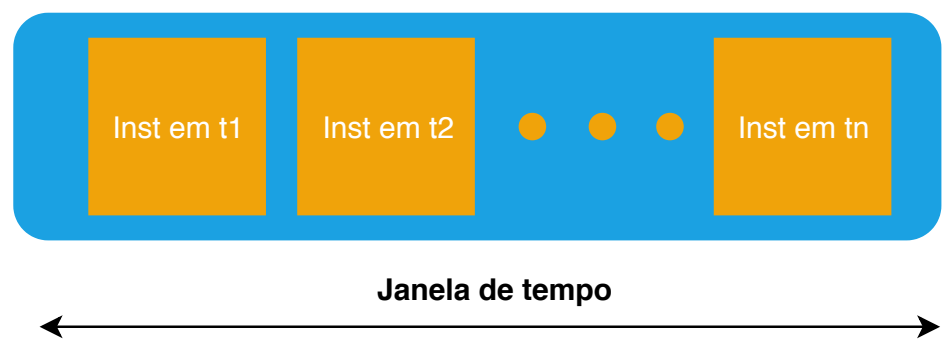

Ameaça detectada

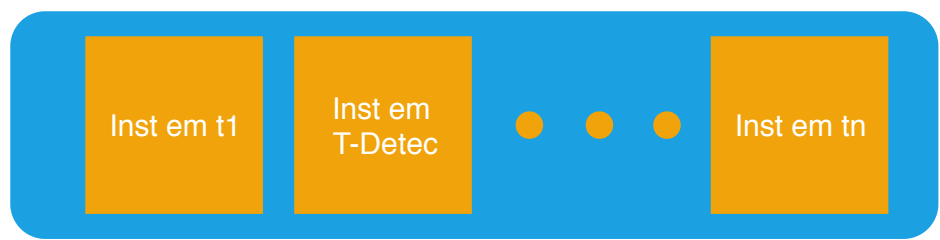

Evidências mantidas - janela crescendo

Fonte: Próprio autor

dade, em Dizang são adotadas duas estratégias: a primeira é a definição de um volume de dados que possa ser considerado suficiente para a realização de uma investigação; a segunda é a definição de uma idade máxima para a evidência enquanto o sistema trabalha em condições normais, isto é, quando não está sob ataque. Para detectar e analisar intrusões na memória de processos, é necessário ter uma cópia da memória antes e depois da intrusão (CASE et al., 2014). Assim, a solução proposta implementa uma janela de instantâneos de memória cobrindo um intervalo de tempo pré-definido, como ilustrado na Figura 8. Em condições normais de operação, as evidências são coletadas com certa periodicidade e coletas que atingem uma determinada idade são descartadas. Em contraste, após a detecção de um evento de ataque (e.g., por um sistema de detecção de intrusões), Dizang deixa de descartar as coletas mais antigas do $\log$ de monitoramento. Como resultado, é possível conhecer o sistema antes e depois do ataque e, assim, avaliar sua evolução. 


\subsection{Garantindo integridade, confidencialidade e prote- gendo privacidade e jurisdição}

Finalmente, para persistir a relação evidência-origem e garantir a sua integridade, Dizang calcula o hash $H$ do par \{evidência, identificador da imagem do contêiner\} e armazena a tripla $\{H$, identificador do recurso, evidência $\}$. Adicionalmente, a presente proposta evita eventuais problemas com o armazenamento desses dados em países com jurisdições diferentes daquelas que devem ser aplicadas na investigação em questão. Especificamente, as evidências coletadas são armazenadas em um local físico fora da nuvem, após serem transportadas por meio de um canal seguro (e.g., via TLS (Transport Layer Security - Camada de Transporte Seguro) (Dierks T, 2008)). Dando ao processo de investigação maior celeridade uma vez que a coleta das evidências já terá ocorrido de forma forensicamente aceitável.

\subsection{Implementação}

Os mecanismos propostos foram implementados em uma plataforma de testes visando avaliar a eficácia de Dizang em coletar as informações de memória dos contêineres de forma reprodutível, sem violar jurisdições ou a privacidade de usuários e a capacidade de detectar injeção de código usando as evidências coletadas. A solução, ilustrada na Figura 9, consistiu na utilização do serviço EC2 para criação de uma instancia t2.micro Ubuntu Server 14.04 LTS de 64 bits (x86) com armazenamento em SSD na zona Ohio da AWS. Nesta instância AWS foi manualmente instalado o Docker Engine 1.10 e a API Docker 1.21, com os quais foram criados 3 contêineres executando o Nginx 1.0 em diferentes portas. Não foram utilizados serviços de contêiner do provedor AWS como EKS ou ECS nos experimentos. Foi desenvolvida uma aplicação Java cujo fluxo é ilustrado na Figura 10 que, executada no sistema operacional hospedeiro, descobre o identificador de processo associado a 
Figura 9: Arquitetura geral da solução Dizang
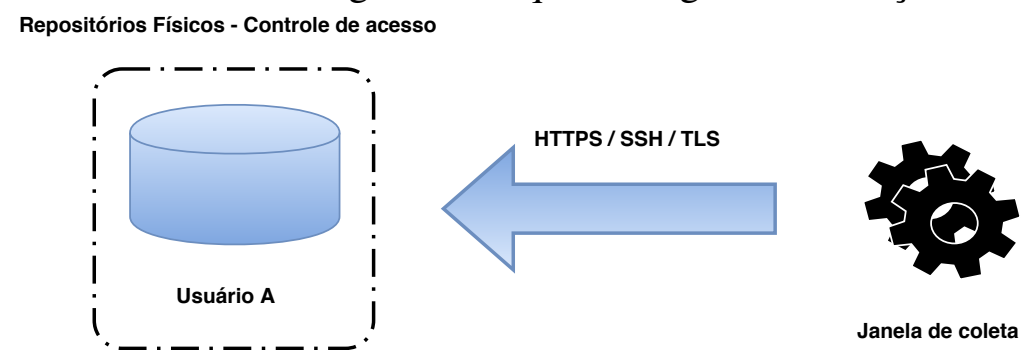

Recurso computacional em nuvem identificável unicamente
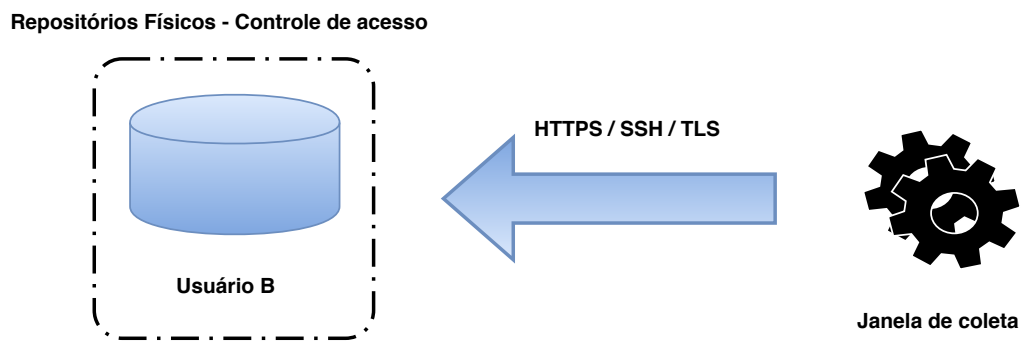

Recurso computacional em nuvem identificáve

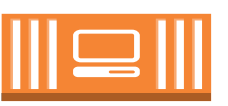

Repositórios Físicos - Controle de acesso
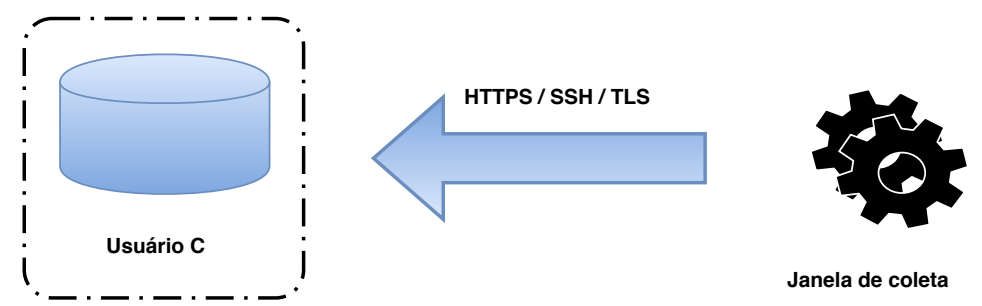

Recurso computacional em nuvem identificável unicamente

Fonte: Próprio autor

cada contêiner, copia o conteúdo do descritor de alocação de memória não uniforme (/proc/pid/numa_maps), o qual contém a alocação das páginas de memória, os nós que estão associados a essas páginas, o que está alocado e suas respectivas políticas de acesso (Unix Man Pages, ). A cópia e gravação do arquivo é tal que, a cada intervalo de tempo $t$, a aplicação (1) pausa o contêiner em questão, (2) copia a diretório numa_maps, (3) concatena os dados obtidos com o identificador da imagem e do contêiner, (4) calcula o $H$ do conjunto e (5) salva o resultado em um arquivo cujo nome é o identificador da imagem e do contêiner e a extensão é .mem. A pausa do funcionamento do contêiner foi materializado através da chamada a API do Docker, http: //<docker-url>:<docker-port>/containers/<id-conteiner $>/$ pause que suspende o funcionamento do contêiner. O transporte seguro da evidência para um 
armazenamento físico fora da AWS foi implementado usando no serviço EC2, uma instância t2.micro Ubuntu Server 14.04 LTS de 64 bits (x86) com armazenamento em SSD na zona Ohio da AWS no qual foi instalado um servidor OpenVPN. Como uma forma básica de controle de acesso, a instância EC2 que contém as evidências foi configurada para aceitar conexões apenas de máquinas nesta VPN. A instância EC2 e a instância da qual foram coletadas as evidências estavam na mesma VPC padrão da AWS Uma máquina física fora da AWS, usou o cliente do OpenVPN para estabelecer uma conexão VPN com a instância que contém as evidências e as transportou para o disco da máquina física. A conexão entre a máquina física fora da nuvem e a instância de EC2 na nuvem foi feita utilizando um provedor de banda larga de uso doméstico de 50Gb (Live Tim). Após a conclusão do processo de transporte, a máquina física verifica se existem arquivos .mem em disco mais antigos que um certo intervalo de tempo $t$, descartando-os.

\subsection{Resultados experimentais}

Para avaliar a efetividade de Dizang na coleta de evidências e identificação de injeção de código, dois experimentos foram realizados usando o ambiente implementado (descrito na Seção 4.4).

\subsubsection{Análise do desempenho}

No primeiro experimento, o sistema foi configurado para realizar coletas de memória em intervalos de 1 minuto, salvá-las em armazenamento externo à nuvem e apagar amostras coletadas há mais de 5 minutos. O sistema foi então executado por 30 minutos, tempo durante o qual foram coletadas como métricas (1) o uso de espaço em disco utilizado pelos instantâneos de memória salvos, (2) o tempo de pausa no contêiner necessário para a cópia delas e (3) o tempo de transporte das evidências para o armazenamento externo a nuvem. 
Figura 10: Fluxo de execução de Dizang para 1 hospedeiro de contêiner

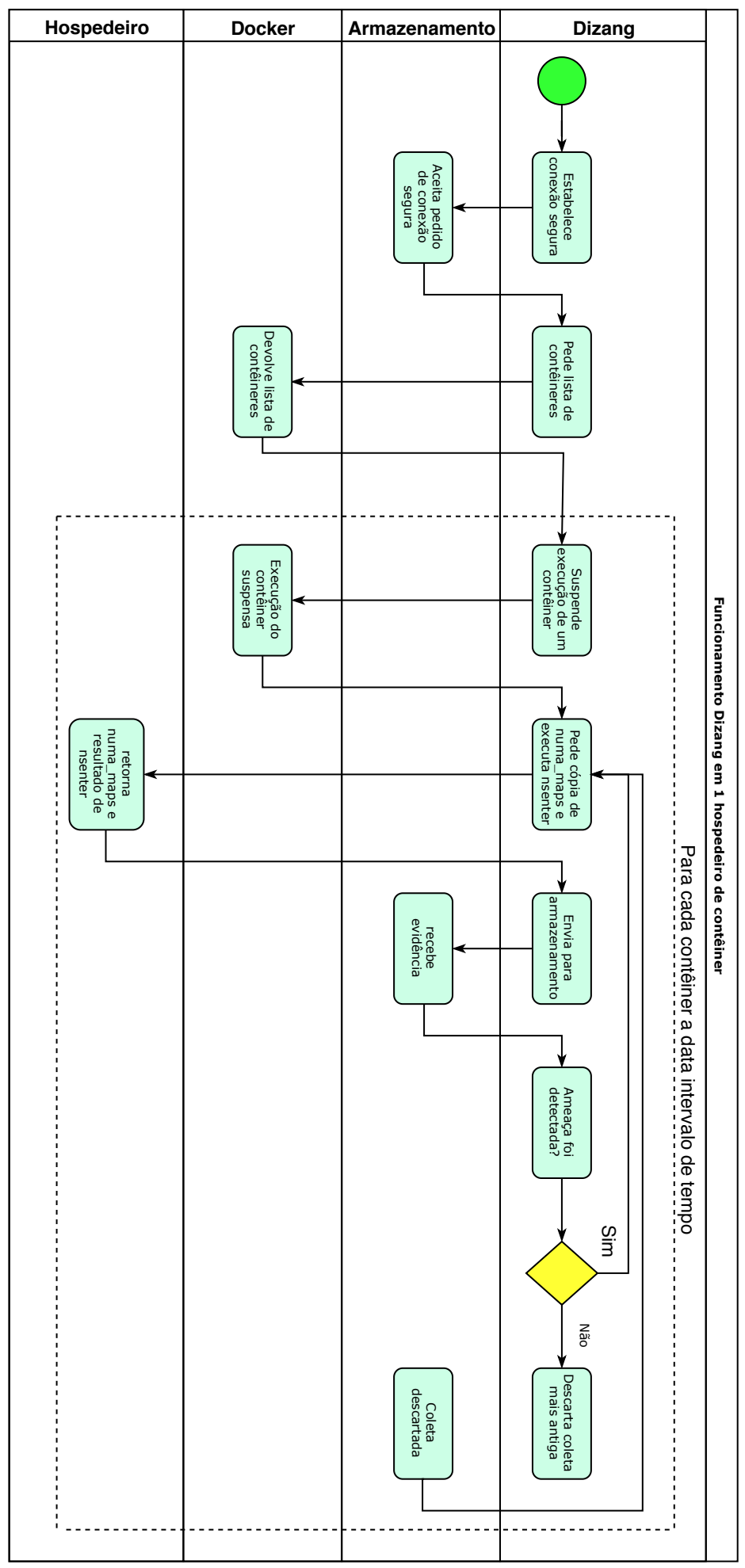

Fonte: Próprio autor 
A evolução do espaço em disco ocupado pelos instantâneos de memória, acompanhado através da execução do comando du -sh * .mem do Unix no disco de armazenamento externo, é mostrada no gráfico da Figura 11. Neste experimento os instantâneos de memória tem $244 \mathrm{~kb}$ de tamanho. O gráfico mostra que o aumento do uso do espaço de armazenamento é linear e o crescimento se interrompe quando é atingido o limite de tempo configurado para a janela, pois as coletas com tempo de vida maior que tal limite são apagadas do armazenamento final. Assim, a solução mantém sob controle o espaço em armazenamento ocupado pelas amostras coletadas. Ao mesmo tempo, instantâneos de memória salvos pela solução depois que os contêineres são removidos continuam no armazenamento da máquina, podendo ser associados a sua origem (i.e., contêiner e imagem), conforme esperado para uma análise forense. Essa capacidade se mantém após a detecção de uma ameaça, pois nesse caso coletas mais antigas deixam de ser apagadas. Logo, é possível descrever o estado do sistema antes e depois do incidente (CASE et al., 2014), permitindo-se, por exemplo, que ataques de injeção de código em memória sejam analisados.

Este experimento usou 3 contêineres para demonstrar que a solução mantém sob controle o espaço em armazenamento ocupado pelas coletas. Segundo (STUBBS; MOREIRA; DOOLEY, 2015) aplicações web modernas são compostas por diversos micro serviços implementados em contêineres. Neste cenário, entende-se que o espaço do armazenamento consumido ainda estaria sob controle porém em um patamar mais elevado uma vez que a quantidade de contêineres seria maior.

Uma potencial limitação da solução proposta é que a pausa de um contêiner para coleta de dados pode, em princípio, causar perdas no desempenho da aplicação sendo executada. Para avaliar esse impacto, durante o experimento foram medidos os tempos de cópia da memória do contêiner. Os resultados são mostrados no gráfico da Figura 12. É possível notar que, após a inicialização da aplicação, o tempo para realizar a cópia é bastante reduzido, variando entre 20 e 40 milissegundos. Em especial, para 
Figura 11: Evolução do uso do espaço em armazenamento com o Dizang

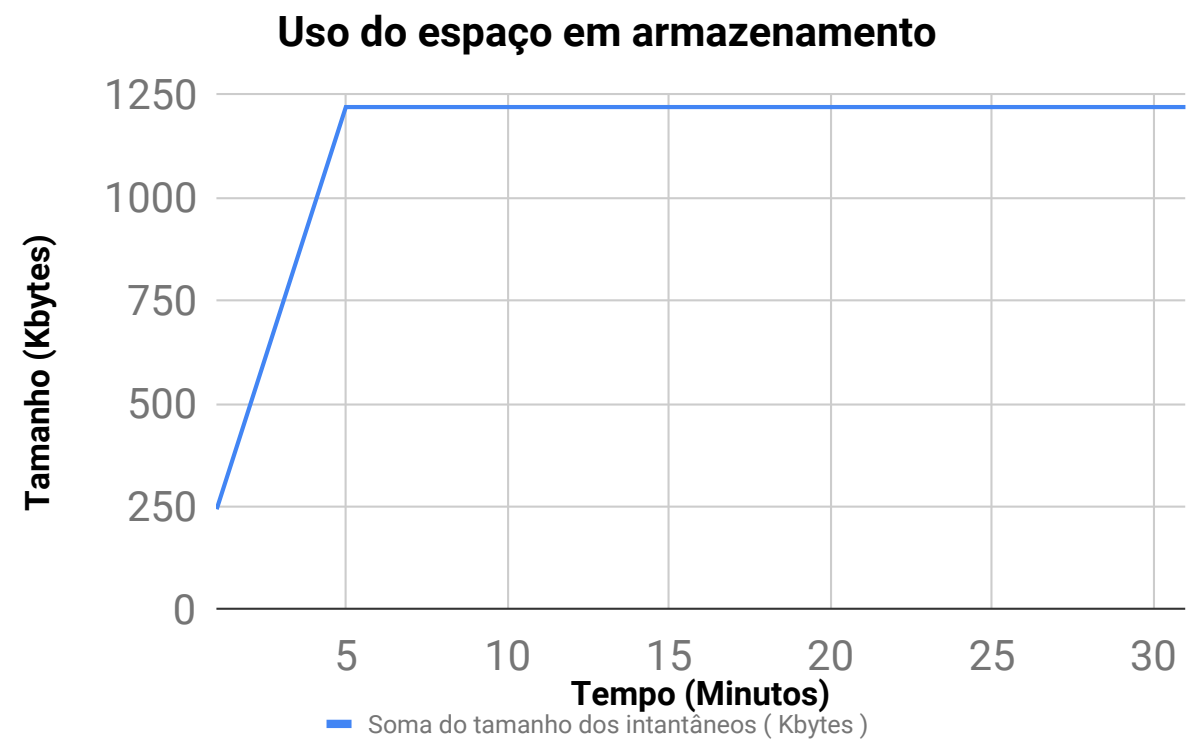

Fonte: Próprio autor

contêineres executando um motor de páginas web dinâmicas, como é o caso do experimento em questão, essa latência deve ser pouco perceptível por usuários finais. Para os casos em que a interrupção da execução do recurso computacional mesmo por breves momentos cause problemas de disponibilidade, é possível realizar o procedimento de coleta em instantes de tempo separados. Assim, ao invés de suspender a execução de todos os recursos computacionais para realização da coleta simultaneamente, o procedimento interrompe-as sequencialmente. Desta forma, a latência demonstrada pode ser considerado o pior caso neste experimento.

Outra preocupação é o tempo de transporte das evidências para o armazenamento fora da nuvem. Caso o transporte da evidência leve mais tempo que a geração do próximo instantâneo, um backlog de transporte se formará levando a perdas nas evidências que estejam pendentes para transporte. Para avaliar esse impacto, durante o experimento foram medidos os tempos de transporte das evidências para o armazenamento fora da nuvem. Os resultados são mostrados no gráfico da Figura 13. É possível notar que o tempo de transporte estabiliza após atingido o tamanho da janela. O tempo 
Figura 12: Tempo de cópia da memória de um contêiner

\section{Tempo de cópia da memória de um contêiner}

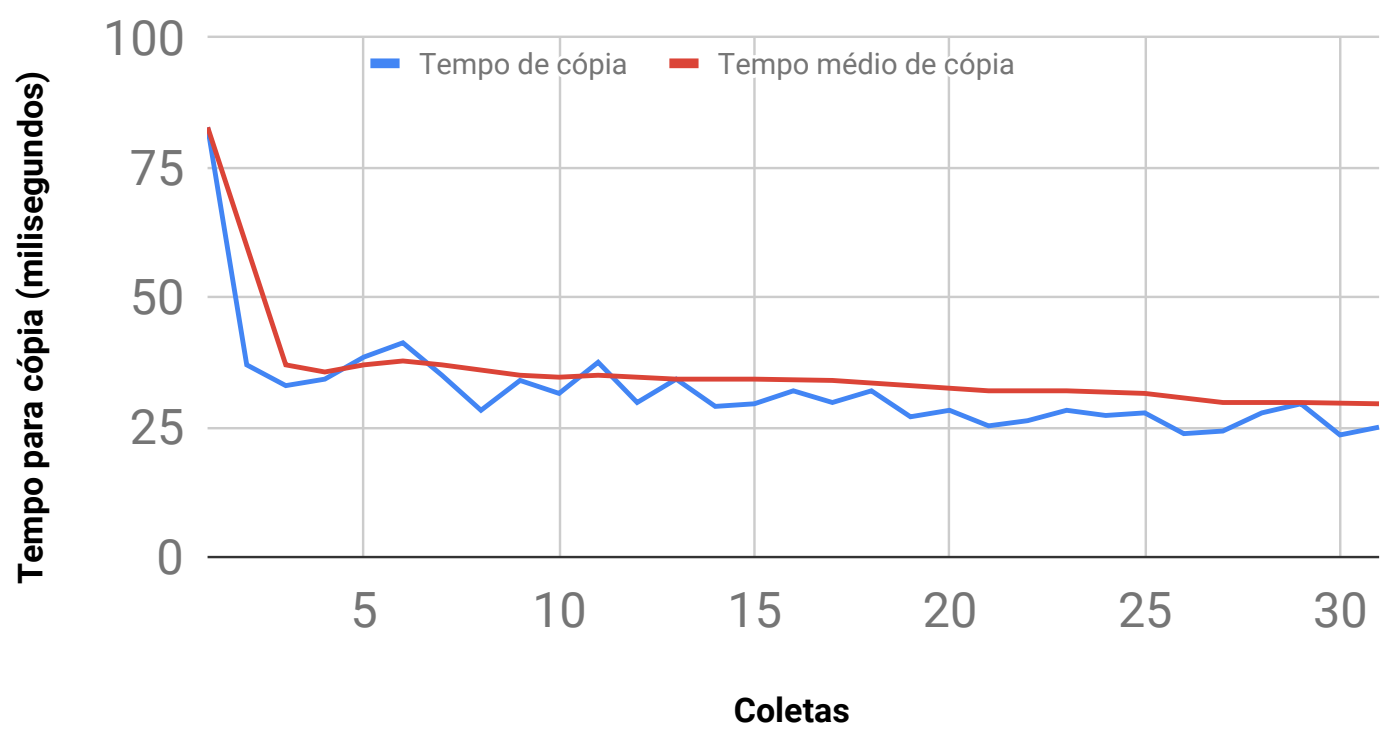

Fonte: Próprio autor

de transporte da evidência fica, em média próximo dos 30 segundos.

Tanto a topologia quando a arquitetura do transporte da evidência e a arquitetura do que se deseja extrair a evidência como a quantidade de contêineres, distribuição geográfica dos hospedeiros, tamanho da evidência de memória, entre outros, são fatores que contribuem tanto positiva quando negativamente no tempo de transporte. Neste experimento o gerador de evidências, um motor de páginas dinâmicas composto por 3 contêineres, está na América do Norte enquanto que a máquina física para onde as evidências foram transportadas e que é responsável pelo transporte da evidência está na América do Sul. Aplicações web modernas compostas por vários micro serviços implementados em contêineres (STUBBS; MOREIRA; DOOLEY, 2015), podem elevar o tempo necessário para Dizang coletar evidências suficientes de modo a ter uma visão do estado da aplicação em um momento $t$. 
Figura 13: Tempo de transporte da evidência

\section{Tempo de transferência da evidência}

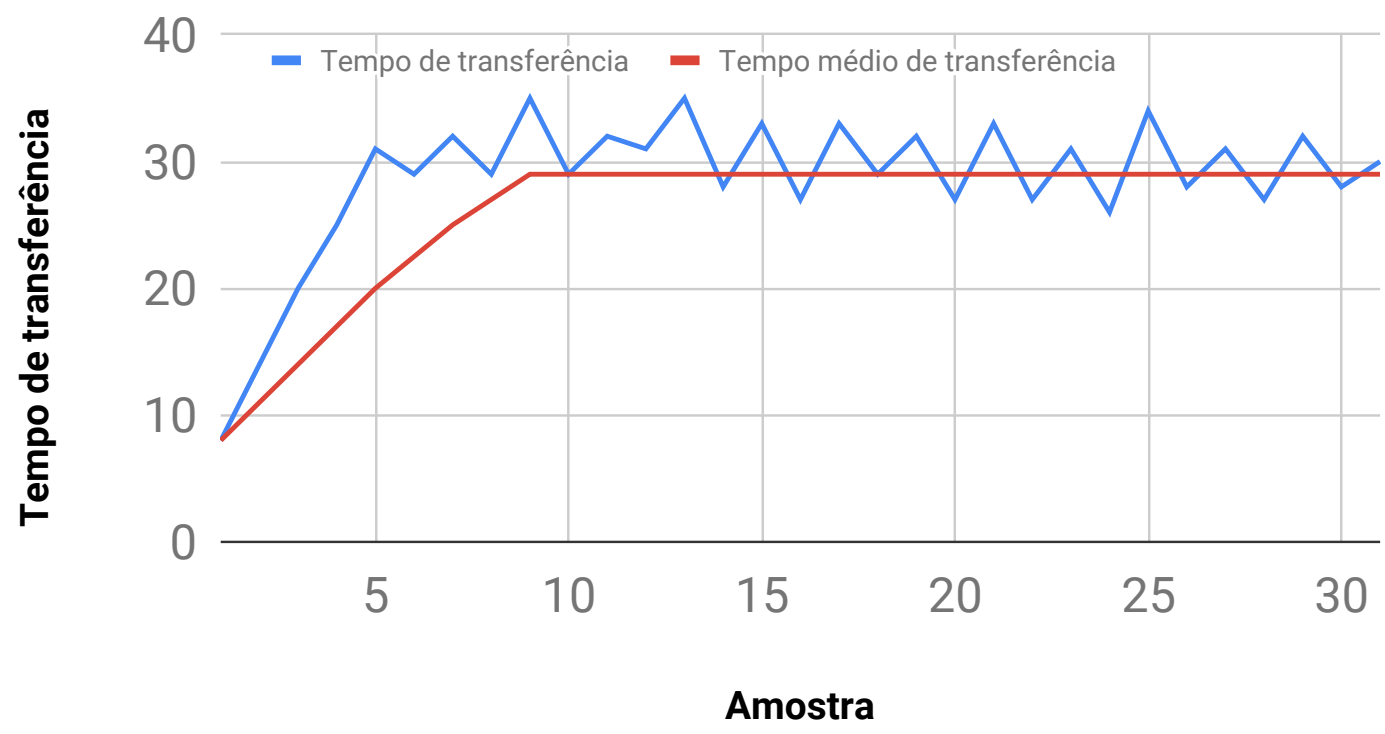

Fonte: Próprio autor

\subsubsection{Identificação de injeção de código malicioso}

Um segundo experimento teve como objetivo determinar se é possível, através da análise das evidências coletadas, identificar injeção de código malicioso na memória do contêiner. Para este fim uma biblioteca libexample.so simulando um código malicioso foi injetado em um dos contêineres. Após cinco minutos de Dizang realizando coletas, uma biblioteca foi injetada na memória de um dos contêineres. Após a injeção permitiu-se que a solução continuasse coletando por mais 5 minutos. Além da coleta do conteúdo do diretório /proc/pid/numa_maps, realizou-se também uma cópia crua da memória do processo do contêiner utilizando o utilitário nsenter via comando descrito na Figura 14.

De posse das coletas do diretório /proc/pid/numa_maps comparou-se dois momentos distintos na vida do contêiner, antes e depois da injeção da biblioteca. Observando as Figuras 15 e 16 é possível notar que no instantâneo após a injeção apa- 
Figura 14: Comando para cópia crua da memória do processo do contêiner sudo ./nsenter --target <pid> --mount --uts --ipc --net --pid

grep rw-p /proc/<pid>/maps I sed -n 's/^([0-9a-f] $\left.{ }^{*}\right)-\left(\left([0-9 a-f]^{*}\right) .{ }^{*} \$ \wedge 1\left|2 / p^{\prime}\right|\right.$ while read start stop; do gdb --batch --pid <pid> -ex "x/4096wx 0x\$start"; done $><$ pid $>$.dump

Fonte: Próprio autor

rece a biblioteca libexample.so simulando o código malicioso entre os endereços 7f85631b8000 e 7f85633b9000. Logo, é possível identificar a injeção de um código malicioso via evidência coletada por Dizang do diretório /proc/pid/numa_maps, permitindo-se por exemplo que ataques de injeção de código sejam identificados. A Figura 17 mostra o conteúdo da parte legível da memória no endereço 0x7f85633b9000 onde a biblioteca libexample.so simulando um código malicioso está alocada.

Figura 15: Parte do arquivo/proc/pid/numa_maps ANTES da injeção 00400000 default file=/home/someuser/target mapped $=1 \mathrm{NO}=1$ 00600000 default file $=/$ home/someuser/target anon $=1$ dirty $=1 \mathrm{NO}=1$ 00601000 default file $=/$ home/someuser/target anon $=1$ dirty $=1 \mathrm{~N} 0=1$ 7fee0b0ed000 default file=/lib/x86_64-linux-gnu/libc-2.19.so mapp... 7fee0b2ab000 default file=/lib/x86_64-linux-gnu/libc-2.19.so 7fee0b4ab000 default file=/lib/x86_64-linux-gnu/libc-2.19.so anon... 7fee0b4af000 default file=/lib/x86_64-linux-gnu/libc-2.19.so anon... $7 f e e 0 \mathrm{~b} 4 \mathrm{~b} 1000$ default anon $=3$ dirty $=3 \mathrm{NO}=3$ 7fee0b4b6000 default file=/lib/x86_64-linux-gnu/ld-2.19.so mapp... 7 fee0b6d1000 default anon $=3$ dirty $=3 \mathrm{NO}=3$ 7 fee0b6d6000 default anon $=2$ dirty $=2 \mathrm{~N} 0=2$ 7fee0b6d8000 default file=/lib/x86_64-linux-gnu/ld-2.19.so anon... 7fee0b6d9000 default file=/lib/x86_64-linux-gnu/ld-2.19.so anon... 7 fee0b6da000 default anon $=1$ dirty $=1 \mathrm{~N} 0=1$ $7 \mathrm{ffc} 91 \mathrm{a} 60000$ default stack anon $=2$ dirty $=2 \mathrm{NO}=2$ $7 f f c 91 b 15000$ default 7ffc91b17000 default

Fonte: Próprio autor

As primeiras tentativas de cópia do conteúdo da memória do processo do contêiner foram feitas via ptrace e não obteve sucesso. Segundo (Fabio Kung, 2017) isto ocorre pois as chamadas de sistema que ferramentas como ptrace e htop usam foram criadas antes da implementação de cgroups no kernel do linux e sendo assim não tem consci- 
Figura 16: Parte do arquivo /proc/pid/numa_maps APÓS a injeção

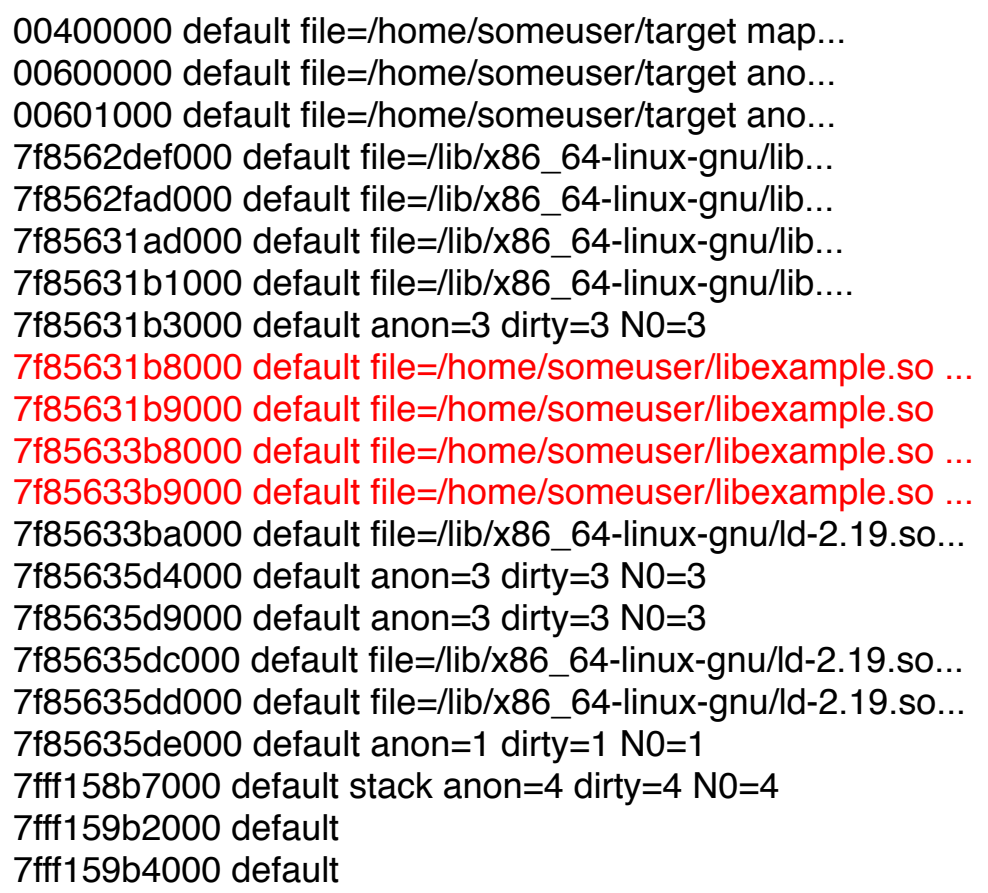

Fonte: Próprio autor

ência da existência de isolamento entre processos. Quando o ptrace tenta acessar uma área de memória isolada por cgroups, o núcleo envia um sinal de violação de acesso de memória.

A documentação do Docker (Docker, 2017) menciona o comando -cap-add=SYS_PTRACE -security-opt-seccomp=unconfined que permite que o ptrace consiga acessar a memória de um processo dentro do contêiner mas não permite que a máquina hospedeira ou outro contêiner tenha acesso (referência). Ainda segundo (Fabio Kung, 2017) uma alternativa para viabilizar a monitoração e acesso a informações de memória seria o de expor tais informações na estrutura de /sys/fs/cgroup/ da mesma forma que é feita para /proc/pid/. O sucesso na cópia do conteúdo da memória do processo do contêiner só foi alcançado quando utilizou-se a ferramenta nsenter. 
Figura 17: Conteúdo da memória de libexample.so no formato [endereço]: [conteúdo]

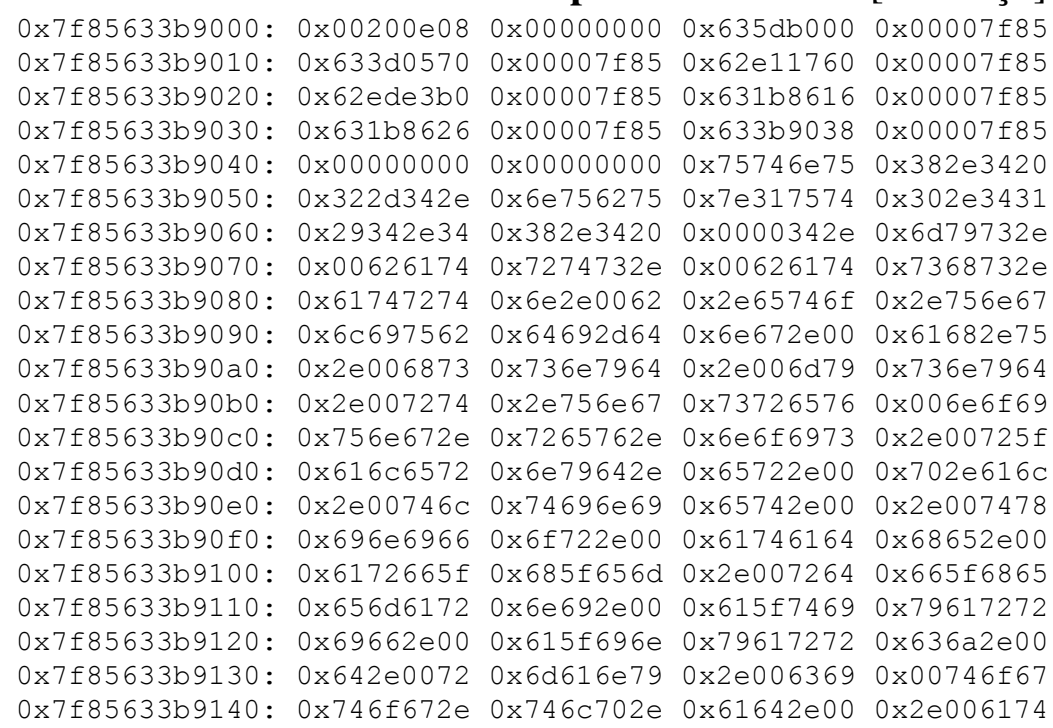

Fonte: Próprio autor

\subsection{Limitações}

A proposta descrita pede que o recurso em nuvem seja identificável de forma única a fim de realizar a associação entre evidência e sua origem. Durante o curso deste projeto essa identificação única só foi possível através do hash da imagem do contêiner. Este foi o único recurso que, submetido ao processo de construção a partir da mesma receita resultou no mesmo hash da imagem. Assim, a implementação para verificação da solução proposta consegue apenas coletar informações de memória no espaço do usuário (user space), ela não consegue acessar o espaço de núcleo do sistema operacional (kernel space). A implementação de Dizang neste documento em princípio não consegue investigar códigos malicioso que se baseiam em informações do kernel space. Isso inclui, por exemplo, a comparação de informações do PEB (Process Environment Block - Bloco para o Ambiente dos Processos), que ficam no user space, com informações do VAD (Virtual Address Descriptor - Descritor de Endereços de Memória Virtual), que fica no kernel space.

Como mencionado em (CASE et al., 2014), "para uma análise eficiente de um in- 
cidente em memória, são necessárias cópias da mesma antes e depois do incidente." Outra limitação da solução proposta é a necessidade da mesma estar instalada no sistema sob investigação a priori para que os resultados descritos neste documento sejam alcançados. Como há uma ampla variedade de ameaças digitais ao largo e novas são criadas constantemente, caso o sistema de detecção de ameaça ao qual Dizang está integrado não conseguir detectar um ataque em andamento, evidências importantes para descrever o sistema antes do ataque podem ser perdidas no descarte do limite da janela. 


\section{CONCLUSÕES}

Ameaças digitais que atuam diretamente na memória de sistema não costumam deixar rastros em disco após terem os recursos correspondentes desalocados, dificultando análises forenses posteriores. Esse problema é especialmente notável em sistemas de computação em nuvem, nos quais a alocação e desalocação de recursos virtualizados (e.g., VMs e contêineres) é frequente. Essa característica, aliada a aspectos como multi-inquilinato e multi-jurisdição de nuvens computacionais, dificulta a coleta de evidências para a investigação de incidentes.

A revisão do estado da arte mostrou que a coleta de evidências forenses em nuvem é uma área de conhecimento com muito espaço para estudo. Os modelos de comercialização e serviços gerenciados e não gerenciados ofertados pelos provedores de nuvem trazem novos desafios para a forense digital a cada dia. Desafios estes tanto técnicos quanto jurídicos.

Nesse cenário, a proposta apresentada visa relacionar o instantâneo de memória a sua origem, identificando univocamente o recurso computacional em nuvem como identificador da origem da evidência armazenada, permitindo conhecer a fonte da evidência mesmo que esta não exista mais e assim contribuir para a credibilidade da evidência. Sem esta capacidade, seria necessário preservar e isolar o recurso virtual para posterior coleta dificultando a utilização de uma arquiteturas auto-escalável. Adicionalmente, para evitar uso excessivo de memória, a quantidade de dados armazenados usa uma janela de armazenamento, o que permite descrever a memória antes e depois 
de um ataque (e.g., de injeção de memória). Tal característica permite manter sob controle a quantidade de dados que os peritos tem que analisar contribuindo para a diminuição da fila de investigação e o aumento da velocidade das investigações. Ainda, ao transportar de forma segura e armazenar a evidência em local conhecido fora da nuvem, evitam-se os problemas relacionados a multi-jurisdição e multi-inquilinato das nuvens computacionais contribuindo para maior celeridade no processo investigativo. Ao mesmo tempo, a comparação de instantâneos de memória coletados em diferentes instantes de tempo permite a identificação de injeção de código assim como extrair o conteúdo da parte legível do endereço de memória correspondente. Combinada com uma ferramenta para identificação de ameaças, essas características de Dizang o transformam em uma solução poderosa para prover evidências e, assim, viabilizar análises forenses na nuvem.

\subsection{Trabalhos Futuros}

Como mencionado em 4.6 a solução proposta é capaz de gerar evidências de memória apenas do espaço do usuário (user space). Alguns códigos malicioso injetados em memória são capazes de manipular o retorno de funções do kernel. Recomenda-se para trabalhos futuros a incorporação à Dizang uma forma de realizar a extração do conteúdo de memória do espaço do kernel (kernel space).

Também discutido em 4.6, as ameaças digitais evoluem constantemente. Algumas dessas novas ameaças podem evadir sistemas de detecção atuais. Caso o sistema de detecção de ameaça ao qual Dizang está integrado não conseguir detectar um ataque em andamento, evidências importantes para descrever o sistema antes do ataque podem ser perdidas no descarte do limite da janela. Recomenda-se para trabalhos futuros um estudo sobre o tamanho de janela ótimo para a operação normal de Dizang , uma que minimize a perda de informação por não detectar que o sistema está sob ataque. 
Em 2.1 foram mencionados os diferentes modelos de comercialização em nuvem. Alguns provedores que possuem modelos de operação PaaS, também ofertam soluções de orquestração de contêineres tais como Docker Swarm (Docker, 2019), Kubernetes (Google, 2019) e Openshift (RedHat, 2019). Tais orquestradores trazem à técnica de conteinerização funcionalidades que podem ser úteis ao funcionamento de Dizang - Sendo assim, recomenda-se para trabalhos futuros um estudo sobre as vantagens que outras tecnologias relacionadas a contêiner possam trazer às métricas de Dizang estudadas neste trabalho.

Por fim, em 4.1 a presente proposta usa o hash de identificação da imagem e do contêiner para associar a evidência a sua origem virtual. Todavia, dependendo da arquitetura utilizada na aplicação sob monitoração de Dizang outras formas de identificação de origem estão disponíveis. Contêineres executando diretamente sobre uma máquina física podem por exemplo se beneficiar da arquitetura de TPM (Trusted Computing Group, 2016) para identificação da origem da evidência. Por isso, como última recomendação para trabalhos futuros, sugere-se um estudo voltado a outras formas de associação da evidência com sua origem virtual. 


\section{REFERÊNCIAS}

Ab Rahman, N. H.; CHOO, K. K. R. A survey of information security incident handling in the cloud. Computers and Security, Elsevier Ltd, vol. 49, p. 45-69, 2015. ISSN 01674048. Available from Internet: < http://dx.doi.org/10.1016/j.cose.2014.11. 006>.

ALQAHTANY, S. et al. Cloud forensics: A review of challenges, solutions and open problems. In Int. Conference on Cloud Computing (ICCC). Plymouth, UK: IEEE, 2015. p. 1-9. Available from Internet: <https://ieeexplore.ieee.org/document/ $7149635>$.

Andrade, Tiago. MapReduce - Conceitos e Aplicações. Campinas, 2008.

BEM, D. et al. Computer forensics - past , present and future. Journal of Information Science and Technology, vol. 5, no. 3, p. 43-59, 2008. Available from Internet: $<$ http://www.cis.gsu.edu/rbaskerville/cis8630/Bernetal2008.pdf $>$.

BERNSTEIN, D. Containers and cloud: From LXC to Docker to Kubernetes. IEEE Cloud Computing, vol. 1, no. 3, p. 81-84, Sept 2014. ISSN 2325-6095. Available from Internet: <https://ieeexplore.ieee.org/document/7036275>.

CASE, A. et al. The Art of Memory Forensics: Detecting malware and threats in Windows, Linux and Mac memory. Hoboken, NJ: Wiley, 2014.

Chef. Chef. 2018. <https://www.chef.io>. Acessado em: 16-04-2018.

CICHONSKI, P. et al. Computer Security Incident Handling Guide. National Institute os Standarts and Technology, 2012. Available from Internet: < http: //dx.doi.org/10.6028/NIST.SP.800-61r2>.

DEZFOULI, F. et al. Volatile memory acquisition using backup for forensic investigation. In Int. Conf. on Cyber Security, Cyber Warfare and Digital Forensic (CyberSec). Plymouth, UK: IEEE, 2012. p. 186-189. ISBN 978-1-4673-6618-2. Available from Internet: <https://ieeexplore.ieee.org/document/6246108>.

Diamant. 2019 CONTAINER ADOPTION BENCHMARK SURVEY. 2019. Available from Internet: <https://diamanti.com/wp-content/uploads/2019/06/Diamanti_2019_ Container_Survey.pdf $>$.

Dierks T, R. E. The Transport Layer Security (TLS) Protocol. Fremont, CA: IETF, 2008. IETF: <https://tools.ietf.org/html/rfc5246>. Acessado em: 15-04-2018.

Docker. Runtime privilege and Linux capabilities. 2017.

Https://docs.docker.com/engine/reference/run/. Acessado em: 30-11-2018. 
. Swarm mode overview. 2019. Https://docs.docker.com/engine/swarm/. Acessado em: 11-12-2019.

DOLAN-GAVITT, B. et al. Virtuoso: Narrowing the semantic gap in virtual machine introspection. In IEEE Symposium on Security and Privacy. Plymouth, UK: IEEE, 2011. p. 297-312. ISSN 1081-6011. Available from Internet: $<$ https://ieeexplore.ieee.org/document/5958036>.

DYKSTRA, J.; SHERMAN, A. Acquiring forensic evidence from infrastructure-asa-service cloud computing: Exploring and evaluating tools, trust, and techniques. Digital Investigation, Elsevier Ltd, vol. 9, p. S90-S98, 2012. ISSN 17422876. (Proc. of the 12th Annual DFRWS Conference). Available from Internet: $<$ http://dx.doi.org/10.1016/j.diin.2012.05.001>.

DYKSTRA, J.; SHERMAN, A. T. Design and implementation of FROST: Digital forensic tools for the OpenStack cloud computing platform. Digital Investigation, Elsevier Ltd, vol. 10, p. S87-S95, 2013. ISSN 17422876. (Proc. of 13th Annual DFRWS Conference). Available from Internet: <http: //dx.doi.org/10.1016/j.diin.2013.06.010>.

Fabio Kung. Memory inside Linux containers. 2017. Acessado em: 3011-2018. Available from Internet: <https://fabiokung.com/2014/03/13/ memory-inside-linux-containers/ $>$.

FEWER, B. S. Reflective DLL Injection. no. October, 2008. Available from Internet: $<$ https://www.dc414.org/wp-content/uploads/2011/01/242.pdf>.

GEORGE, S.; VENTER, H.; THOMAS, F. Digital Forensic Framework for a Cloud Environment. In IST Africa Conference Report. Tanzania: IIMC, 2012. p. 1-8. ISBN 978-1-905824-34-2. Available from Internet: <https: //pdfs.semanticscholar.org/104f/cc8b4b9ddc4926d76bb85ce564adcaaf70b4.pdf > .

GOOGLE. GRR Rapid Response. 2013. <https://grr-doc.readthedocs.io/en/v3.2.1/what-is-grr. html>. Acessado em: 27-07-2019.

Google. Kubernetes. 2019. Https://cloud.google.com/kubernetes/. Acessado em: 11-12-2019.

GRISPOS, G.; STORER, T.; GLISSON, W. Calm before the storm: the challenges of cloud computing in digital forensics. International Journal of Digital Crime and Forensics, vol. 4, no. 2, p. 28-48, 2012. ISSN 1466640073. Available from Internet: $<$ www.igi-global.com/article/calm-before-storm/68408>.

HBase. HBaset. 2018. <https://hbase.apache.org/>. Acessado em: 16-06-2018.

JIANG, D.; SHENG, N. DCFF: a container forensics framework based on Docker. 3rd International Conference on Materials Engineering, Manufacturing Technology and Control (ICMEMTC 2016), p. 1644-1650, 2016. 
KEYUN, R. et al. Advances in Digital Forensics VII. In GILBERT, P.; SUJEET, S. (Ed.). 7th IFIP WG 11.9 International Conference on Digital Forensics. 7. ed. Orlando: [s.n.], 2011. vol. 1, chap. 3. ISBN 9788578110796. Available from Internet: $<$ https://www.springer.com/gp/book/9783642242113>.

LEE, J.; UN, S. Digital Forensics as a Service: A case study of forensic indexed search. p. 499-503, 2012. Available from Internet: < https://ieeexplore.ieee.org/ document/6387185>.

LINUXCONTAINERS.ORG. Linux Containers (LXC). 2015. <https://linuxcontainers. org/lxc/introduction/>. Acessado em: 20/05/2017.

LUIS, P.; SANCHEZ, P.; GIOVA, G. Digital Chain of Custody Quality Assessment. International Journal of Computer Science and Network Security (IJCSNS), vol. 16, no. 4, p. 41-48, 2016. ISSN 17387906. Available from Internet: $<$ https://www.researchgate.net/publication/303250922_Digital_Chain_of_Custody_ Quality_Assessment>.

MELL, P.; GRANCE, T. The NIST definition of cloud computing. 2011.7 p. NIST SP 800-145. Available from Internet: <http://csrc.nist.gov/publications/nistpubs/ 800-145/SP800-145.pdf $>$.

MILLER, M.; TURKULAINEN, J. Remote Library Injection. 2004. Tech. Report: $<$ http://www.hick.org/code/skape/papers/remote-library-injection.pdf $>$.

MORSY, A. M.; GRUNDY, J.; MULLER, I. An Analysis of the Cloud Computing Security Problem. In APSEC Cloud Workshop. Sydney, Australia: Cornell University, 2010. Available from Internet: <https://arxiv.org/abs/1609.01107>.

POISEL, R.; MALZER, E.; TJOA, S. Evidence and cloud computing: The virtual machine introspection approach. Journal of Wireless Mobile Networks, Ubiquitous Computing, and Dependable Applications, vol. 4, no. 1, p. 135-152, 2013. ISSN 20935374 (ISSN). Available from Internet: <http://citeseerx.ist.psu.edu/viewdoc/ summary?doi=10.1.1.469.937>.

Portworx. 2018 CONTAINER ADOPTION SURVEY. 2018. Available from Internet: <https://portworx.com/wp-content/uploads/2018/12/ Portworx-Container-Adoption-Survey-Report-2018.pdf $>$.

Puppet. Puppet. 2018. <https://puppet.com/>. Acessado em: 16-04-2018.

QUICK, D.; CHOO, K. K. R. Impacts of increasing volume of digital forensic data: A survey and future research challenges. Digital Investigation, Elsevier Ltd, vol. 11, no. 4, p. 273-294, 2014. ISSN 17422876. Available from Internet: <http://dx.doi.org/10.1016/j.diin.2014.09.002>.

RAFIQUE, M.; KHAN, M. N. A. Exploring Static and Live Digital Forensics: Methods, Practices and Tools. International Journal of Scientific $\mathcal{F}$ Engineering Research, vol. 4, no. 10, p. 10481056, 2013. Available from Internet: <www.ijser.org/researchpaper/ Exploring-Static-and-Live-Digital-Forensic-Methods-Practices-and-Tools.pdf $>$. 
RAHMAN, N. H. A.; CAHYANI, N. D. W.; CHOO, K.-K. R. Cloud incident handling and forensic-by-design: cloud storage as a case study. Concurrency Computation Practice and Experience, p. 685-701, 2016. Available from Internet: $<$ https://www.researchgate.net/publication/303373633_Cloud_incident_handling and_forensic-by-design_cloud_storage_as_a_case_study_Cloud_Incident_Handling_ and_Forensic-by-Design $>$.

RAHMAN, S.; KHAN, M. N. A. Review of live forensic analysis techniques. International Journal of Hybrid Information Technology, vol. 8, no. 2, p. 379388, 2015. Available from Internet: < https://www.researchgate.net/publication/ 283740637_Review_of_Live_Forensic_Analysis_Techniques $>$.

RAMOS, M. G. Do Valor Probatório do Arquivo Digital. PhD Thesis (PhD) — Universidade de Brasilia, 2011. Available from Internet: < http://bdm.unb.br/ bitstream/10483/1843/1/2011_MonicaGomesRamos.pdf>.

RedHat. Openshift. 2019. Https://www.openshift.com/. Acessado em: 11-12-2019.

REICHERT, Z.; RICHARDS, K.; YOSHIGOE, K. Automated forensic data acquisition in the cloud. IEEE Int. Conf. on Mobile Ad Hoc and Sensor Systems, p. 725-730, 2015. Available from Internet: < https://ieeexplore.ieee.org/document/ $7035772>$.

Right Scale. State of the Cloud Report. 2018. Available from Internet: <www.suse. com/media/report/rightscale_2018_state_of_the_cloud_report.pdf $>$.

SANG, T. A log-based approach to make digital forensics easier on cloud computing. 2013 3rd International Conference on Intelligent System Design and Engineering Applications, ISDEA 2013, p. 91-94, 2013. Available from Internet: $<$ https://ieeexplore.ieee.org/document/6454779>.

SIBIYA, G.; VENTER, H.; THOMAS, F. Digital Forensics in the Cloud: The State of the Art. In CUNNINGHAM, P.; CUNNINGHAM, M. (Ed.). IST-Africa 2015. Milongwe, Malawi: [s.n.], 2015.

SIMOU, S. et al. Cloud forensics: Identifying the major issues and challenges. In Advanced Information Systems Engineering (CAiSE 2014). Cham, CH: Springer International Publishing Switzerland 2014, 2014. vol. 8484, p. 271284. ISBN 9783319078809. ISSN 16113349. Available from Internet: <https: //www.researchgate.net/publication/289531775_Cloud_Forensics_Identifying_the_ Major_Issues_and_Challenges>.

STACK, O. Open Stack Framework. 2018. <https://www.openstack.org>. Acessado em: 20-05-2018.

STUBBS, J.; MOREIRA, W.; DOOLEY, R. Distributed Systems of Microservices Using Docker and Serfnode. In 7th International Workshop on Science Gateways. Texas: [s.n.], 2015. p. 34-39. ISBN 9781467374590.

Trusted Computing Group. TPM. 2016. Https://trustedcomputinggroup.org/. Acessado em: 11-12-2019. 
Unix Man Pages. Numa Maps - Non Uniform Memory Architecture. <http: //man7.org/linux/man-pages/man7/numa.7.html>. Acessado em: 24-06-2017.

. cgroups - Control Groups. 2017. <http://man7.org/linux/man-pages/man7/cgroups.7.

$\overline{\mathrm{html}}$. Acessado em: 15-09-2017.

. chroot - Change Root coomand. 2017. <http://man7.org/linux/man-pages/man1/chroot.

1.html>. Acessado em: 24-09-2017.

. $d d$ - convert and copy a file. 2017. <http://man7.org/linux/man-pages/man1/dd.1.html>.

Acessado em: 01-12-2017.

. Namespacing. 2017. <http://man7.org/linux/man-pages/man7/namespaces.7.html>.

Acessado em: 15-09-2017.

Vagrant. Vagrant. 2018. <https://www.vagrantup.com/>. Acessado em: 16-04-2018.

VöMEL, S.; STüTTGEN, J. An evaluation platform for forensic memory acquisition software. In . Amsterdam, The Netherlands, The Netherlands: Elsevier Science Publishers B. V., 2013. vol. 10, p. S30-S40. ISSN 1742-2876. Elsevier Science Publishers. Available from Internet: < http://dx.doi.org/10.1016/j.diin.2013.06.004>.

WEN, Y. et al. Forensics-as-a-Service (FaaS): Computer Forensic Workflow Management and Processing Using Cloud. CLOUD COMPUTING 2013, The Fourth International Conference on Cloud Computing, GRIDs, and Virtualization, p. 208-214, 2013. 